\title{
Current perspectives in the management of keratoconus with contact lenses
}

\author{
Li Lim ${ }^{1,2,3} \cdot$ Elizabeth Wen Ling Lim ${ }^{4}$
}

Received: 9 November 2019 / Revised: 30 May 2020 / Accepted: 22 June 2020 / Published online: 8 July 2020

(c) The Author(s), under exclusive licence to The Royal College of Ophthalmologists 2020

\begin{abstract}
Our aim is to review current and significant articles on contact lens wear in keratoconus patients. A comprehensive literature search of PubMed was performed for the following topics on contact lens wear in keratoconus patients: (1) characteristics of contact lens wearers, (2) safety and efficacy, (3) complications, (4) fitting techniques, (5) contact lens wear after procedures/ surgeries, (6) patient satisfaction. A total of 104 studies were finally selected and reviewed. Gas permeable (GP) lens wear provided significantly better vision than glasses. Special cone design lenses had better patient comfort levels though there was no difference in best corrected visual acuity among the GP lenses. Soft lenses showed good efficacy for the treatment of mild-to-moderate keratoconus with newer designs improving visual performance such as customised hydrogel and novel pinhole lenses. Scleral and hybrid lenses provide good visual acuity and comfort for keratoconic patients previously intolerant to RGP lenses. RGP lens wear post-cross linking (CXL) is relatively well-tolerated. Contact lenses may still be required post intrastromal corneal ring procedures and post keratoplasty. Scheimpflug imaging and anterior segment optical coherent tomography (ASOCT) are useful in contact lens fitting. Computerized contact lens fitting techniques could reduce the chair time of lens fitting as well as improve comfort and visual performance. Contact lenses play an important role in the visual rehabilitation of keratoconus patients. New contact lens designs and materials have significantly expanded the available fitting options for keratoconus patients. Imaging technology can be utilized to guide contact lens fitting.
\end{abstract}

\section{Introduction}

Keratoconus is a progressive noninflammatory ectatic disorder of the cornea characterized by thinning and protrusion of the cornea leading to irregular astigmatism, myopia and poor vision [1]. It is the most common corneal ectatic condition with a prevalence of about 54 per 100,000 people in the United States [2]. A more recent nation-wide study performed in the Netherlands showed that the estimated

Li Lim

lim.li@ singhealth.com.sg

1 Singapore National Eye Centre, 11 Third Hospital Avenue, Singapore 168751, Singapore

2 Singapore Eye Research Institute, 20 College Road Discovery Tower Level 6, The Academia, Singapore 169856, Singapore

3 Duke-NUS Medical School, 8 College Road, Singapore 169857 , Singapore

4 Yong Loo Lin School of Medicine, National University of Singapore, 1E Kent Ridge Road, Singapore 119228, Singapore prevalence of keratoconus in the general population is 1:375 (265 cases per 100,000, 95\% CI: 260-270) which are five to ten times higher than previously reported values in population studies [3]. The mean age at diagnosis is 28.3 years with $60.6 \%$ of patients being male [3]. Risk factors include both genetic and environmental factors such as eye rubbing, personal history of atopy, and family history of keratoconus [4]. Due to its chronic and debilitating nature, keratoconus has a significant impact on vision-related quality of life (VRQoL) [5]. Hence the management of keratoconus patients involves long term care with the need for nonsurgical and surgical management options.

The corneal ectasia preferred practice pattern by the American Academy of Ophthalmology contains useful clinical guidelines for the overall management (nonsurgical and surgical) of keratoconus [6]. In the early stages of keratoconus, the vision could be corrected with glasses. However, in the moderate to advanced stages, spectacles play a limited role and contact lenses may be required for vision correction [7]. The global consensus on keratoconus and ectatic diseases recognized the importance of contact lenses in the visual rehabilitation of these patients. They 
recommend that rigid contact lenses be used in cases of unsatisfactory vision with glasses or conventional soft contact lenses (SCLs). In a patient who has failed a trial of corneal gas permeable (GP) lenses, the alternative contact lens options include hybrid (rigid center, soft skirt), toric, bitoric, keratoconus design SCLs, keratoconus design corneal GP contact lenses, piggy-back, corneoscleral, miniscleral, and scleral lenses [8].

The recent U.S. Food and Drug Administration approval of corneal cross-lining (CXL) provides an option that may slow or halt the progression of keratoconus. In recent years, there have been advances in the surgical management of keratoconus with surgical procedures such as CXL, topography guided excimer laser treatment combined with CXL, intrastromal corneal ring procedures performed alone or in combination with CXL, intraocular contact lenses performed alone or in combination with CXL, and anterior lamellar keratoplasty procedures. While these procedures have resulted in better visual outcomes, contact lens wear may still be required in postoperative visual rehabilitation.

With recent developments in contact lens properties and design, a greater range of contact lens options are available for patients with corneal irregularities. These options include larger diameter GP lenses, scleral lenses, hybrid lenses, and custom soft lenses. The ultimate aim is to optimise visual outcomes, patient satisfaction, and comfort for keratoconus patients using contact lenses. The benefits of new and more comfortable contact lens designs, combined with CXL's effect on progression, should continue to reduce the number of individuals needing some form of keratoplasty procedure.

The purpose of this paper is to provide a review of current and significant articles focusing on the safety and efficacy of contact lenses in the visual rehabilitation of keratoconus.

\section{Methods}

A comprehensive literature search of PubMed, an electronic database, was performed up to 17th February 2019. The keywords used were: "contact lens", "rigid contact lens", "rigid gas permeable", "RGP", "Rose K contact lens", "soft contact lens", "scleral contact lens", "miniscleral contact lens", "piggyback contact lens", "prosthetic contact lens", "PROSE", "hybrid contact lens", "eye print pro", "keratoconus", "KC", "corneal ectasia", "ectasia", "Scheimpflug", "anterior segment optical coherence tomography", and "ASOCT". Using this method, 699 search results were generated. The references of retrieved articles were also searched for other relevant articles. Publications in English on the following topics on contact lens wear in keratoconus patients were included in our review: (1) characteristics and survey of contact lens wearers, (2) safety and efficacy, (3) complications, (4) fitting techniques, (5) contact lens wear after cross-linking, intracorneal ring segment insertion or penetrating keratoplasty (PK), (6) satisfaction and quality of life. Publications which did not contain information of interest were excluded. A total of 104 studies were finally selected and reviewed. In this paper, GP lenses refer to corneal GP lenses (older term RGP lenses).

\section{Results and discussion}

\section{Characteristics and survey of contact lens wear in keratoconus patients}

Cohort and cross-sectional studies show that the majority of keratoconus patients wearing contact lenses are fitted with corneal GP lenses. (Table 1). All the different types of contact lenses mentioned in this paper have been tabulated for easy reference (Table 2).

Long-term studies (Collaborative Longitudinal Evaluation of Keratoconus (CLEK) and the Dundee University Scottish Keratoconus Study (DUSKS)) show that most patients are fitted with contact lenses when vision can no longer be corrected to at least 20/30 with glasses $[9,10]$. Longitudinal and cross-sectional studies worldwide on the characteristics and survey of contact lens wear in keratoconus patients show that GP lenses remain the mainstay treatment for keratoconus [11-16], with the majority of keratoconus patients attaining good visual acuity (VA) with lens wear. In the (CLEK) study looking at patients with moderate to severe keratoconus (95\% had steep keratometry of $>45 \mathrm{D}), 74 \%$ of patients wore contact lenses, $16.1 \%$ wore spectacles, and $3.6 \%$ had no vision correction $[11,16]$. The CLEK population had good visual outcomes with $78 \%$ of patients achieving a best corrected visual acuity (BCVA) of $20 / 40(6 / 12)$ or better in both eyes. $65 \%$ of patients wore GPs in both eyes and most of them (73\%) reported that their lenses were comfortable. Most GP lenses (88\%) were fitted with apical touch $[11,16]$. In the DUSKS study, contact lens wear was the mainstay of treatment $(76 \%$ of 200 patients wore contact lenses) with $91 \%$ wearing GP lenses, $6 \%$ wearing hybrid contact lenses, and $2 \%$ wearing scleral lenses [9]. In another longitudinal study, due to good visual outcomes, contact lens wear delayed the need for surgery in keratoconus patients in $98.9 \%$ of eyes [17].

In a study on 130 keratoconus patients (228 eyes) in the United Kingdom, GP lenses of the spherical, elliptical and special cone lens design were used in $96.1 \%$ of eyes [12]. With contact lens wear, $87 \%$ achieved a VA of 6/9 (20/30) or better and $65 \%$ were able to wear their lenses for more than $12 \mathrm{~h}$ a day [12]. Another cross-sectional study in New Delhi showed similar findings with $99.9 \%$ of eyes wearing 


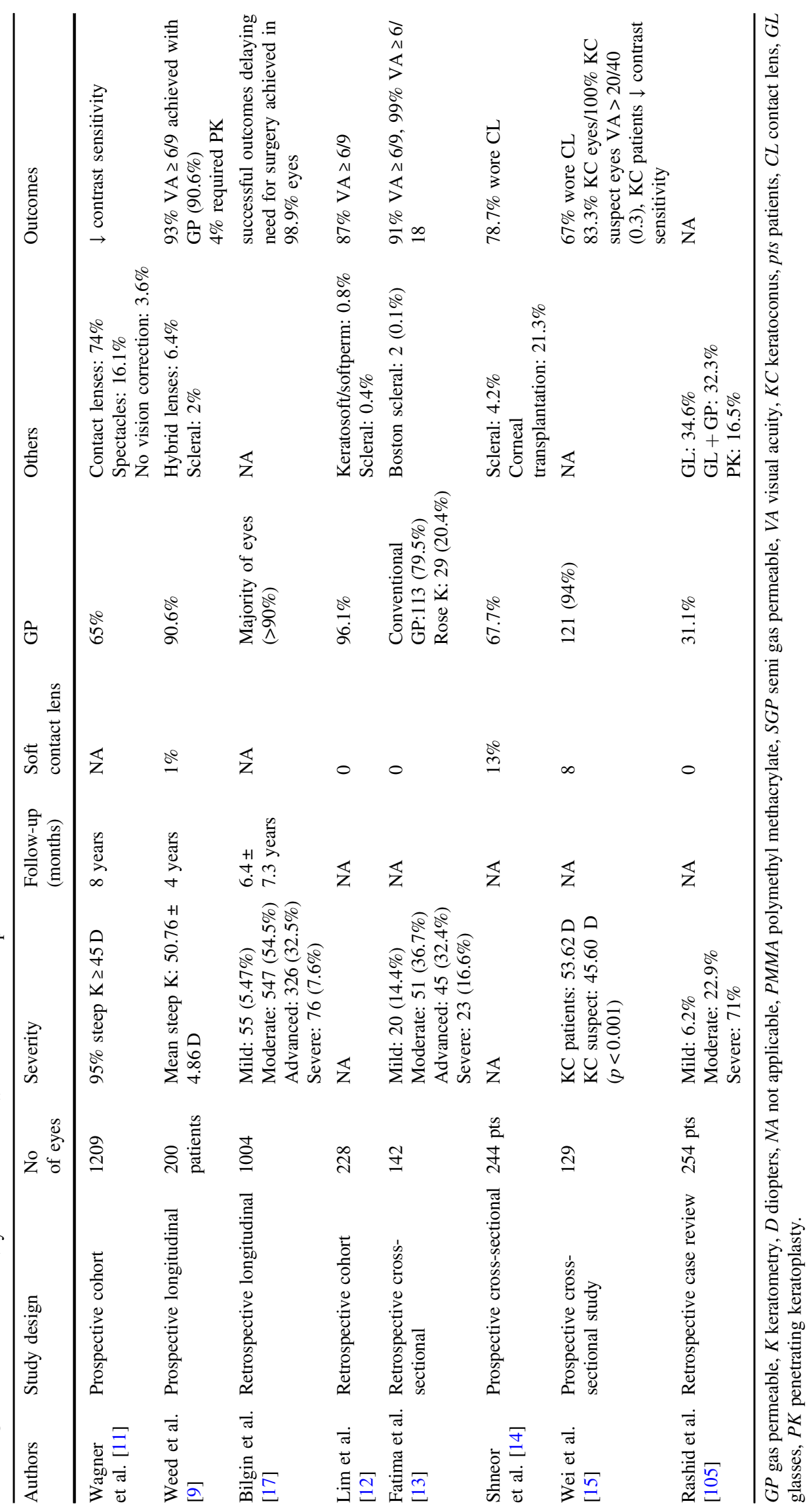




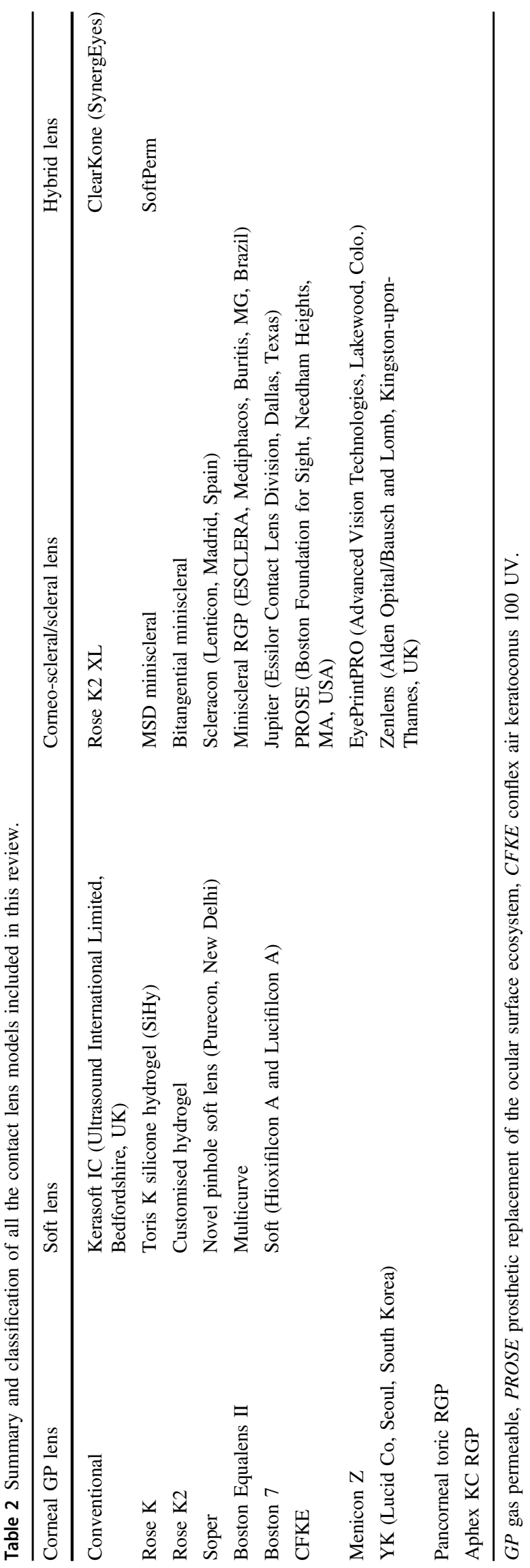

GP lenses (79.5\% conventional GP, 20.4\% Rose K) and $91 \%$ of eyes achieving a VA of $6 / 9$ (20/30) or better [13]. Conventional GP lenses refer to non specialty design GP lenses. In Israel, similar results were also found in a crosssectional study which reported that $78.7 \%$ of patients wore contact lenses (67.7\% RGP, $13 \%$ soft CL, $4.2 \%$ scleral) and $21.3 \%$ of patients had undergone corneal graft surgery [14]. In Singapore, $67 \%$ of keratoconus patients wore contact lenses with $94 \%$ of them wearing GP lenses [15]. With contact lens wear, $83.3 \%$ of keratoconus eyes and $100 \%$ of keratoconus suspect eyes achieved a VA of 0.3 (decimal) (20/40). In the United Kingdom, Pullum et al. studied the characteristics of 538 patients with scleral contact lens wear over a 5-year period and found that primary corneal ectasia accounted for $61.4 \%$ of eyes [18].

Recent advances in surgical options for keratoconus include cross-linking, intracorneal rings, photorefractive keratometry, phakic intraocular lenses, and anterior lamellar keratoplasty. Although it would be important to compare the results of surgery and contact lens wear for a similar disease stage, there is currently no published literature on this subject.

\section{Contact lens efficacy and comfort}

\section{Comparative studies-GP and soft/scleral/hybrid lenses}

Comparative studies show that specialty design contact lenses, new design scleral lenses and hybrid lenses had better patient comfort levels than conventional GP lenses (Fig. 1, Table 3).

Many comparative studies compared the efficacy and comfort of GP lenses with other lens types or glasses. Among GP lens types, Rose $\mathrm{K}$ had better patient comfort levels [19, 20]. Most studies reported that GP lens wear provided significantly better vision and improved threedimensional depth perception as compared with glasses though there was no difference in best contact lens corrected visual acuity (BCLCVA) among the GP lenses (Boston Equalens II, Boston 7, CFKE, Rose K, and Rose K2) [20, 21]. There was also no difference in BCLCVA between Rose $\mathrm{K}$ and Kerasoft IC contact lenses for the treatment of mild-to-moderate keratoconus [22]. The study by Betts et al. reported no improvement in the VA in keratoconic patients wearing Rose $\mathrm{K}$ as compared with habitual lenses, though comfort levels were significantly higher, with $72 \%$ of patients stating that they preferred Rose $\mathrm{K}$ lenses over their habitual lenses and $87 \%$ reporting that they would continue wearing Rose K lenses [23].

A new randomized controlled study by Levit et al. compared the efficacy and comfort of Rose $\mathrm{K}$ and Zenlens (a Scleral lens manufactured in Boston XO2 material, Alden Optical/Bausch and Lomb, Kingston-upon-Thames, 

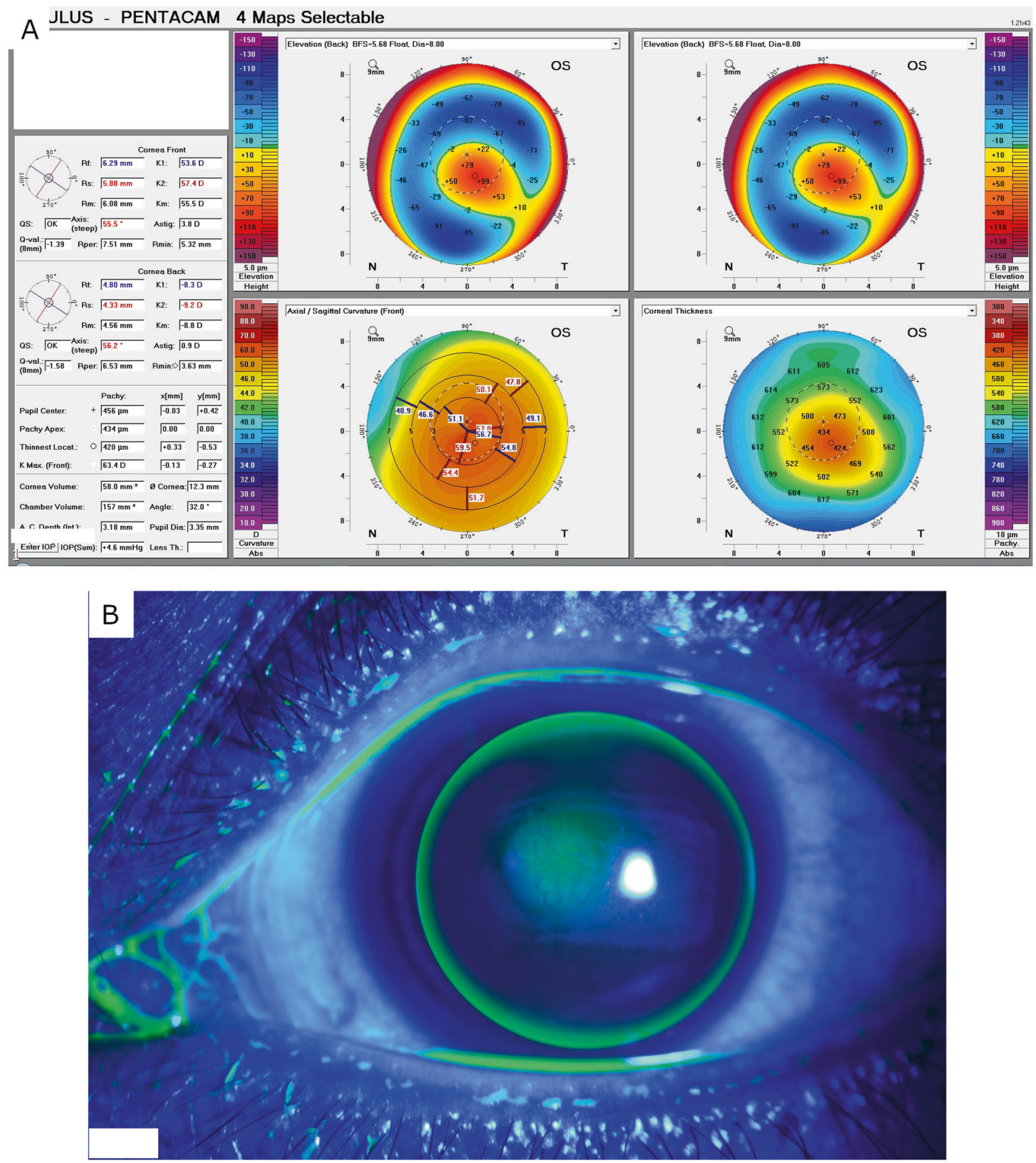

Fig. 1 Left eye Rose K2 GP lens fitted in a patient with advanced keratoconus. a Left eye Pentacam tomography: central conical pattern shown on the keratometry map. b Left eye cobalt blue filter image with fluorescein dye showing an apical clearance fit pattern. (Left eye: maximum keratometry $57.4 \mathrm{D}$; minimum keratometry $53.6 \mathrm{D}$; Rose K2 GP lens $6.30 \mathrm{~mm} \mathrm{BC/-8.25} \mathrm{D/8.7} \mathrm{mm} \mathrm{Dia.).}$
UK) [24]. It found no significant difference in VA $(P=$ $0.563)$ or contrast sensitivity $(P=0.316)$. However, scleral lens wearers had higher subjective comfort scores $(P=$ 0.002) [24].

When comparing GP/habitual lenses to hybrid lenses, visual outcome is equivocal with two studies showing that
ClearKone (SynergEyes) hybrid lens wear had improved VA as compared with GP/habitual lens [25, 26] while Hashemi et al. did not find a significant difference between these two lenses [27]. Contrast sensitivity was shown to be better in ClearKone lens wearers as compared with GP lenses [26]. Patient satisfaction and VRQoL were better in 


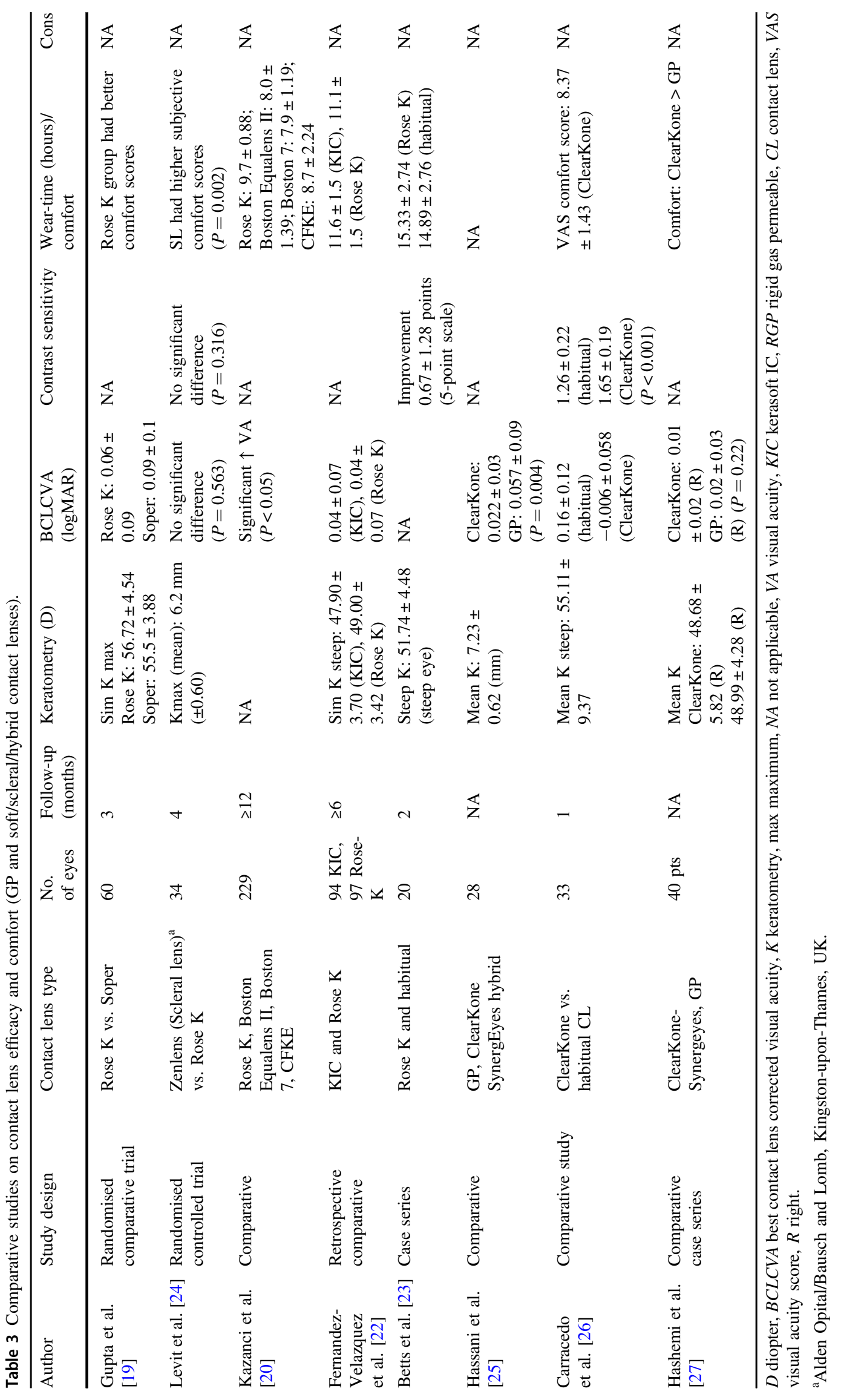


those who used ClearKone lenses [26, 27]. Between hybrid lenses, the ClearKone lens has a better oxygen permeability at the central cornea, $2.0 \mathrm{~mm}$ and $4.5 \mathrm{~mm}$ temporal to the central cornea as compared with the SoftPerm lens as the soft lens material in ClearKone is silicone hydrogel (SiHy) compared with hydrogel material in the SoftPerm lenses [28]. SoftPerm lenses have since been discontinued in 2010 due to oxygen permeability issues.

In summary, the comparative studies show that newer specialty design keratoconus GP lenses had better comfort levels than conventional or habitual GP lenses although there was no difference in the BCVA between the two groups. For mild-to-moderate keratoconus, soft keratoconus design lenses (Kerasoft IC) attained similar BCLVA to Rose $\mathrm{K}$ lenses with better comfort levels achieved. The new hybrid lens (ClearKone) had better patient satisfaction and VRQoL than GP/habitual lenses. A new scleral lens design (Zenlens) was more comfortable than Rose $\mathrm{K}$ lens.

\section{Non-comparative studies-soft lenses}

Studies show that soft lenses are able to provide satisfactory vision in mild-to-moderate keratoconus (Table 4). Newly designed soft lenses, customized hydrogel lenses and pinhole contact lenses widen the scope of vision correction of keratoconus with soft lenses.

Three non-comparative case series performed on soft lenses show good efficacy for the treatment of mild-to-moderate keratoconus. Sultan et al. showed that Toris K SiHy soft lenses are an effective alternative to GP lenses for the treatment of all grades of keratoconus (Amsler-Krumeich classification grades 1-4; mean keratometry 49.42 D), with no significant difference in BCVA with the two lenses [29]. The Toris $\mathrm{K}$ lenses are newly designed SiHy lenses with a toric front surface that is able to improve visual performance. Customised hydrogel contact lenses which incorporate vertical coma correction have also been found to improve both monocular and binocular visual performance in patients with mild-to-moderate keratoconus [30]. Higher order aberrations in patients with keratoconus can also be eliminated by wearing a novel pinhole soft lens (Purecon, New Delhi: 2.5 $\mathrm{mm}$ clear pupil, $8.3 \mathrm{~mm}$ base curve, $11.9 \mathrm{~mm}$ iris diameter, and $13 \mathrm{~mm}$ overall diameter) [31]. The pinhole effect is able to correct the aberropia caused by higher order aberrations such as vertical coma in patients with keratoconus.

\section{Non-comparative studies-GP lenses}

Case studies performed on GP lenses show that they are effective for the treatment of keratoconus and lens wear is comfortable (Table 4). The type of GP lens most frequently used depends on the severity of keratoconus, with monocurve GP lenses most frequently fitted in patients with mild- to-moderate keratoconus while bicurve GP lenses more frequently fitted in patients with severe and advanced keratoconus [32]. Two types of GP lenses (Menicon Z and YK) have comparable efficacy and comfort. YK lenses (Lucid Co, Seoul, Korea) are proprietary multicurve GP lenses for keratoconus. Menicon Z GP lenses are effective with an $82 \%$ success rate (as defined by VA, comfort, and corneal physiology) and a mean duration of wear of 2.5 years [33]. YK lenses have also been shown to be effective with $94.5 \%$ of eyes achieving a VA of 20/40 (6/12) or better (average VA $0.79 \pm 0.21$ Snellen decimal). It also has relatively high patient comfort levels, with $97.6 \%$ of eyes tolerating the contact lens with a mean wearing time of $12.1 \mathrm{~h}$ per day and $90.7 \%$ reporting that the lenses were comfortable [34]. In another study reported by Lee et al., YK lenses improved efficacy and comfort in keratoconus patients [35]. Overall, $71.6 \%$ of eyes achieved a VA of $20 / 30$ or better, $94 \%$ tolerated the fitting, $85 \%$ reported complete comfort, and the mean wearing time was $11.9 \mathrm{~h}$ per day [35].

\section{Non-comparative studies—scleral and hybrid lenses}

Fitting corneal GP lenses in advanced cases of keratoconus can be challenging as a result of lens decentration, dislocation, or discomfort. Scleral and hybrid lenses have been shown to provide good VA and comfort for keratoconic patients, some of whom were previously intolerant to RGP (Table 5, Figs. 2-5). The advantages of scleral lenses over GP lenses are increased comfort and stability of lens wear. Scleral lenses with their large diameter allow for vaulting over the irregular and steep corneas and therefore have an increasing role in the treatment of corneal ectasia, providing another viable nonsurgical option. In general, scleral lenses are more comfortable than corneal GP lenses since there is no contact with the cornea which has more innervation than the sclera. Also, their larger diameter results in a more comfortable lens-to-lid interaction. In the recent years, newer scleral lens designs have expanded the scope of contact lens wear in keratoconus patients. The current recommendation by the Scleral Lens Education Society is to move away from using diameter classification in scleral lens nomenclature since it would not be accurate for extremely large or small eyes [36]. Instead, scleral lenses are classified based on the resting zone area of the lens on the ocular surface. Corneal lenses (Fig. 1) are lenses which rest entirely on the cornea, corneo-scleral lenses (Figs. 2-4) are lenses which rest partly on the cornea and partly on the sclera and scleral lenses (Fig. 5) are lenses which rest entirely on the sclera [36]. In this paper, we will use this new classification and refer to semi-scleral lenses as corneoscleral lenses (Table 6).

The Rose K2 XL lens, a corneo-scleral contact lens, provided good visual acuity (BCLCVA $0.09 \log$ MAR) and 


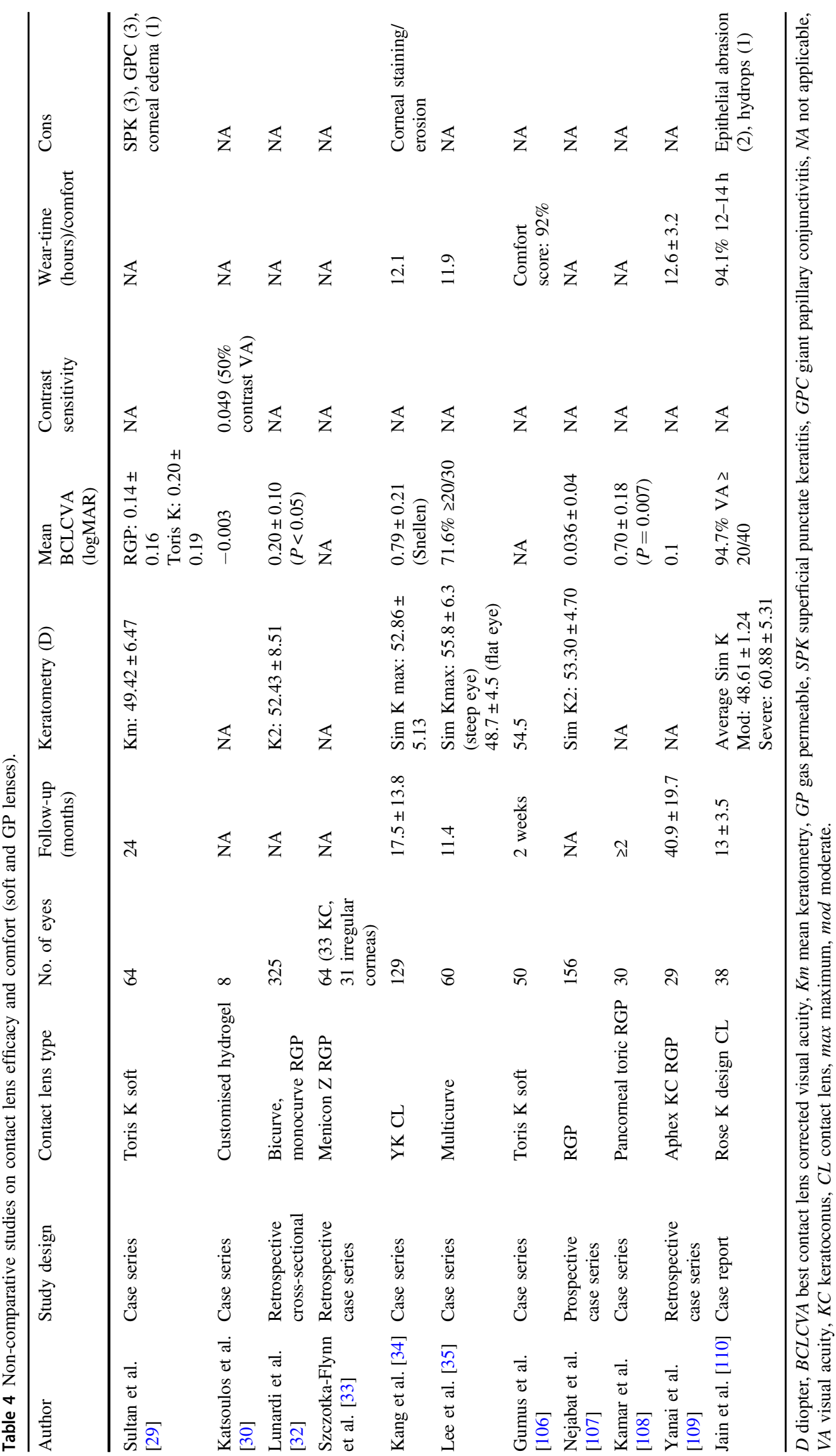




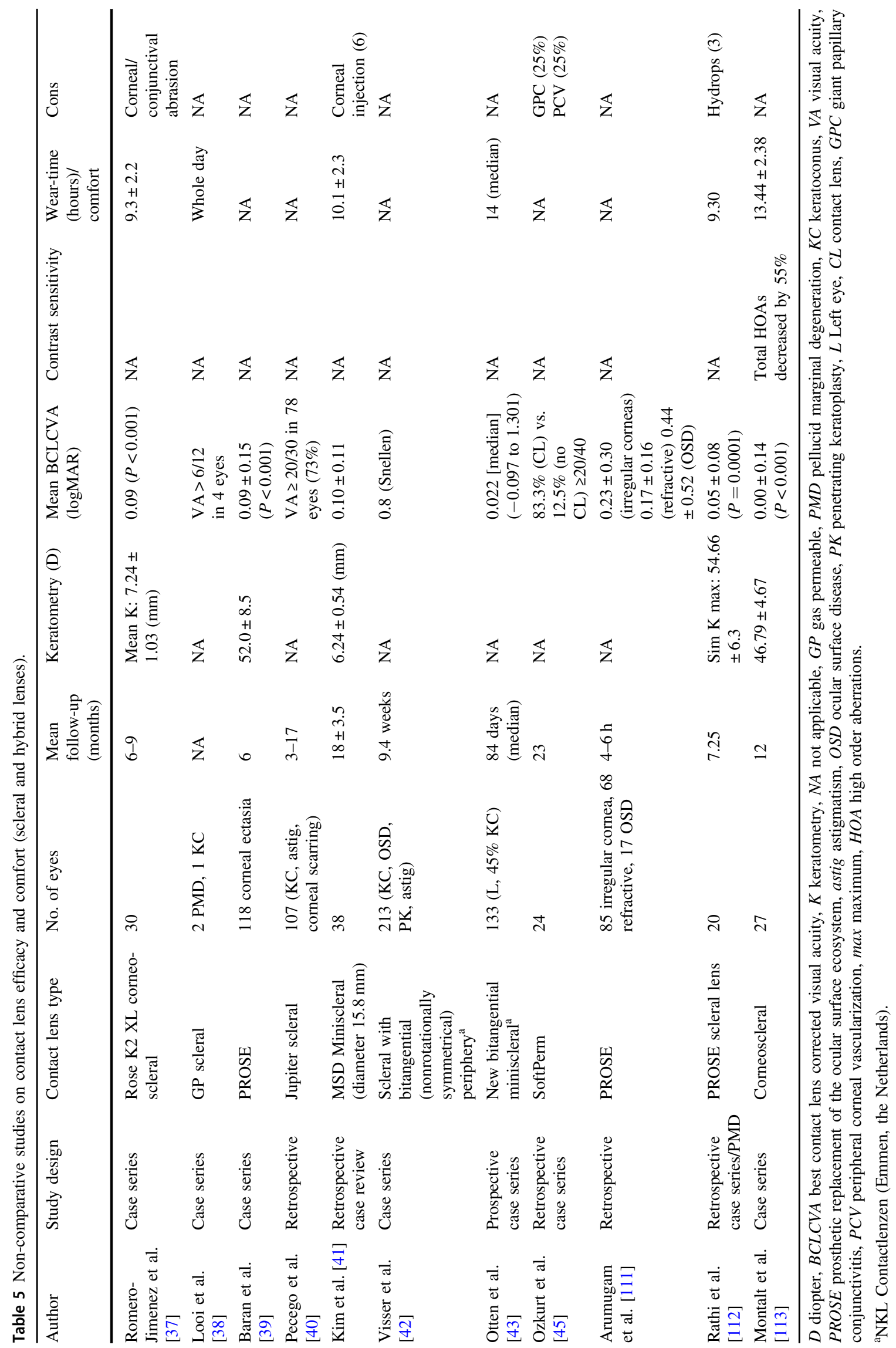



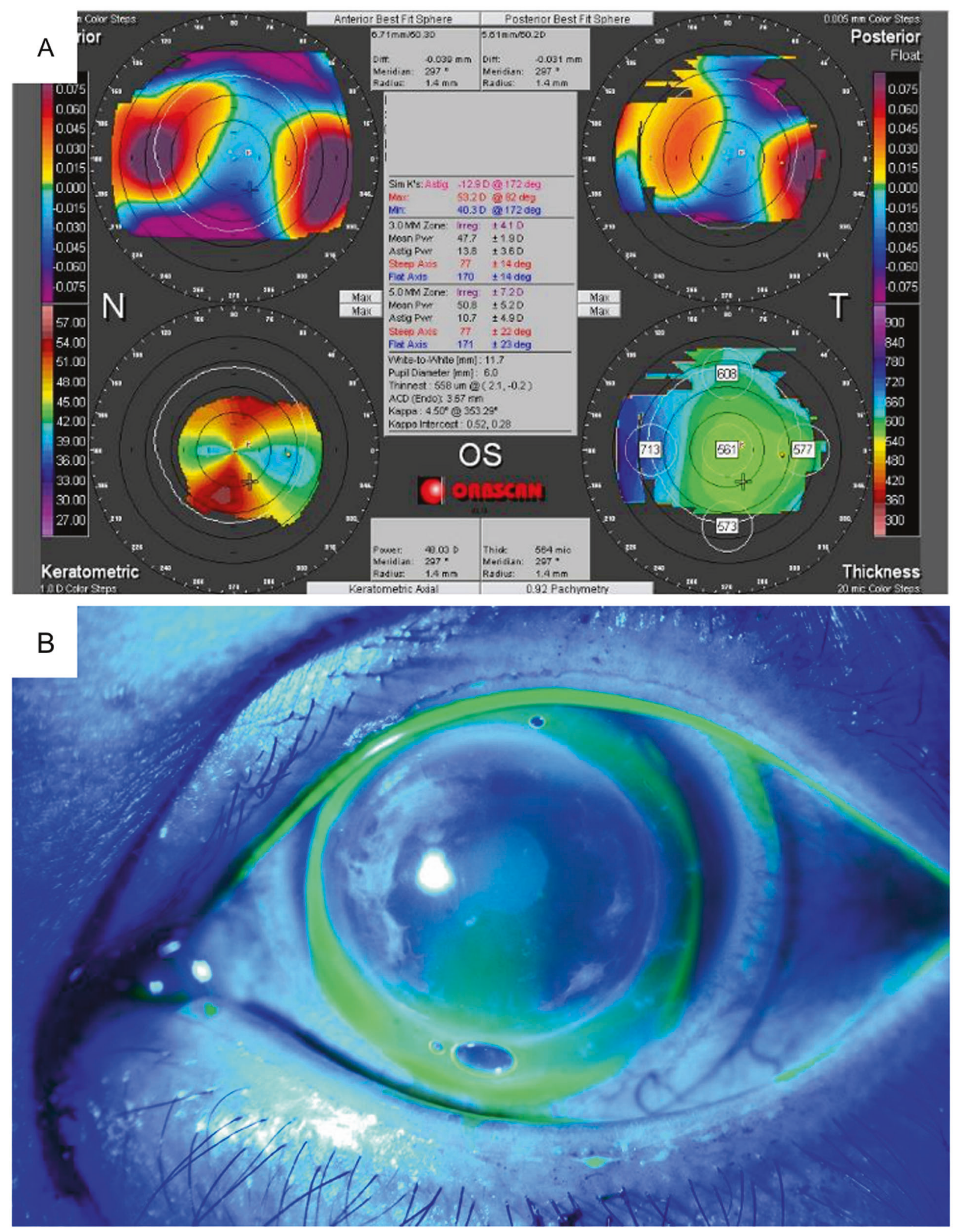

Fig. 2 Left eye Rose $K$ corneo-scleral lens fitted in a postpenetrating keratoplasty patient. a Left eye Orbscan topography: vertical bowtie pattern on the keratometry map showing residual high with-the-rule astigmatism. b Left eye cobalt blue filter image with fluorescein dye showing an apical clearance fit pattern. (Refraction: $+2.75 /-12.50 \times 165^{\circ}$ [6/9]; Rose K corneo-scleral lens $6.40 \mathrm{~mm}$ $\mathrm{BC} /-11.00 \mathrm{D} / 14.40 \mathrm{~mm}$ Dia [6/7.5]). 

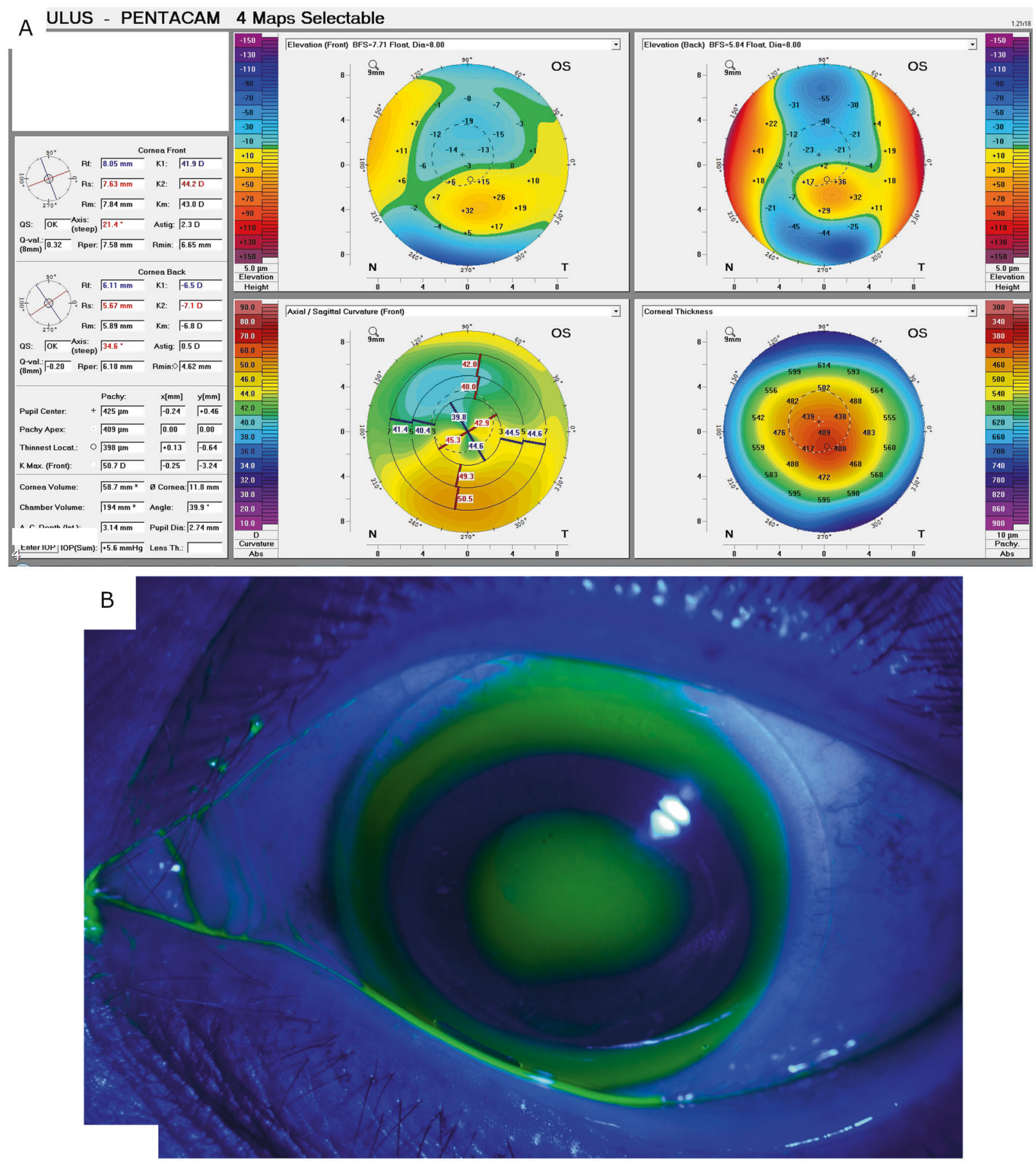

Fig. 3 Left eye Capricornia corneo-scleral lens fitted in a postLASIK ectasia patient. a Left eye Pentacam tomography showing an inferior steepening pattern on keratometry map with corresponding posterior elevation on the posterior elevation map. b Left eye cobalt

comfort for patients with irregular corneas [37]. In patients unsuitable for conventional GP lens wear, scleral lens wear could be a good alternative, with all patients in a study achieving a BCLCVA of $6 / 12(20 / 40)$ or better [38]. In patients with corneal ectasia, prosthetic replacement of the blue filter image with fluorescein dye showing an apical clearance fit pattern. (Refraction: $-0.25 /-4.00 \times 105^{\circ}$ [6/6]; Capricornia corneoscleral lens $7.00 \mathrm{~mm} \mathrm{BC/-7.75} \mathrm{D/13.50} \mathrm{mm} \mathrm{Dia} \mathrm{[6/6]).}$

ocular surface ecosystem (PROSE) custom lens wear has been shown to be effective with a lens wear of $88 \%$ at 6 months and an improvement in NEI VFQ-25 score of 27.6 points $(p<0.001)$ on a 100-point scale [39]. PROSE custom lenses are designed by using proprietary computer-assisted 

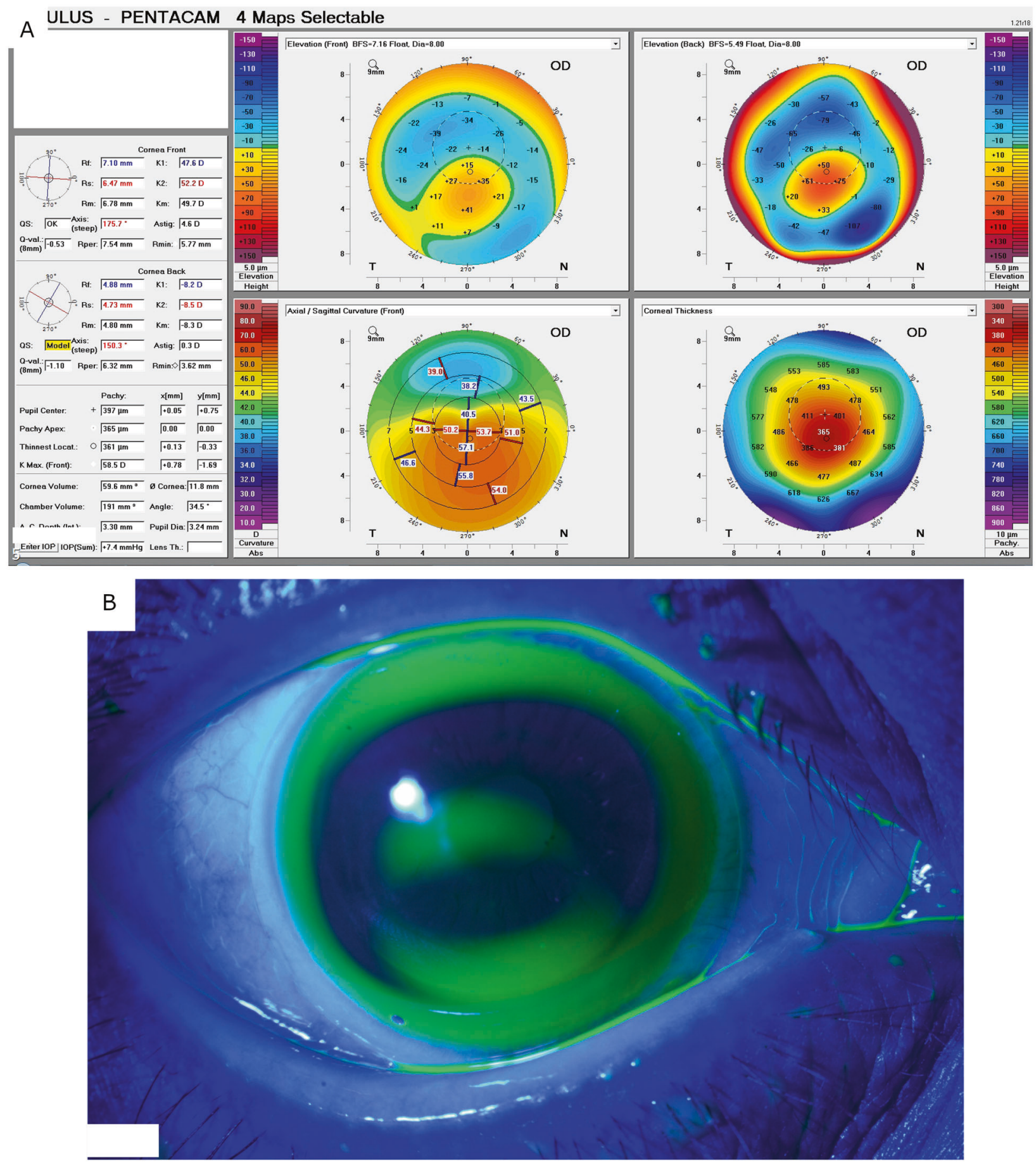

Fig. 4 Right eye Capricornia corneo-scleral lens fitted in a postLASIK ectasia patient. a Right eye Pentacam tomography showing an inferior steepening pattern on keratometry map with corresponding posterior elevation on the posterior elevation map. b Right eye cobalt blue filter image with fluorescein dye showing an apical bearing fit pattern. (Refraction: pl/-8.00 $\times 95^{\circ}$ [6/15]; Capricornia corneo-scleral lens $6.80 \mathrm{~mm} \mathrm{BC/}-10.50 \mathrm{D} / 13.50 \mathrm{~mm}$ Dia [6/7.5]). design and manufacture US patented software that is linked to a manufacturing lathe to create a smooth lens surface and to allow for control of the vault of the lens independent of base curve radius. PROSE treatment is an excellent alternative to keratoplasty for eyes with ectasia that are contact lens intolerant. Jupiter scleral lenses $(15.0-24.0 \mathrm{~mm}$ in diameter) have also been shown to produce good results with $73 \%$ of patients reporting a BCLCVA of 20/30 (6/9) or better and $78 \%$ finding the lens comfortable in a study by Pecego et al. [40]. In a Korean population, MSD miniscleral 

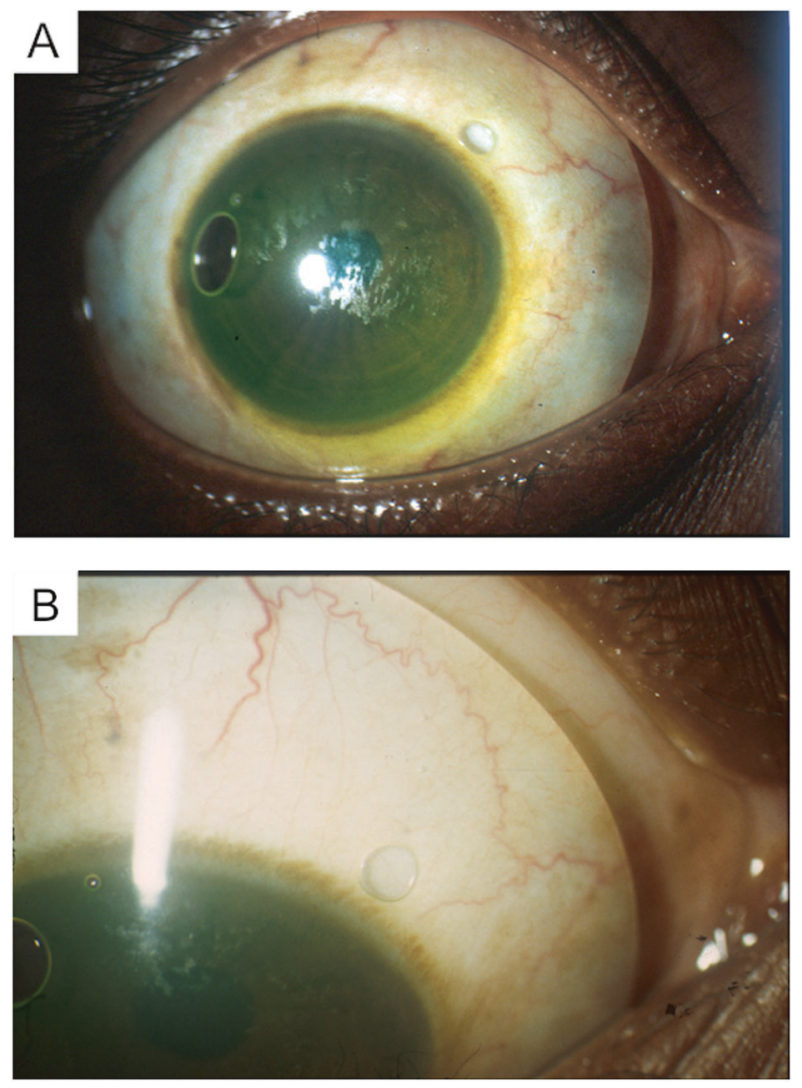

Fig. 5 Right eye scleral lens fitted in a patient with advanced keratoconus intolerant to GP lenses. a Right eye slit lamp photograph showing a well centered scleral lens with adequate corneal clearance. b Adequate scleral lens edge lift with no blanching of the conjunctival vessels seen. (F4 lens [Innovative Sclerals, UK] 8.27BC/ $-0.25 \mathrm{D} / 14.50 \mathrm{~mm}$ scleral radius $/ 23 \mathrm{~mm}$ overall diameter [6/9]).

lenses $(15.8 \mathrm{~mm})$ are also suitable for keratoconus patients, with a mean $\log$ MAR acuity of $0.10 \pm 0.11$. Overall, $97 \%$ of patients reported comfortable lens wear and the mean daily lens wear time was $10.1 \pm 2.3 \mathrm{~h}$ [41]. Bitangential scleral lenses $(20 \mathrm{~mm})$ are effective for keratoconus with a median decimal BCVA of 0.8 in one study [42]. Bitangential scleral lenses have a non-rotationally symmetrical periphery that aims to enable gentle positioning on the scleral surface, increasing fitting tolerance and optimal centration. A new bitangential mini-scleral lens has also been developed by Otten et al. (Visser Contact Lens Practice, NijmegenUtrecht, the Netherlands) (median diameter $16 \mathrm{~mm}$; range: 15.5-17 mm). These lenses provided good VA with a median BCLCVA of 0.022 (logMAR) and were comfortable (79\% reported a comfort score of either a 4 or 5 (out of $5), 82 \%$ wore their lenses $12 \mathrm{~h}$ or longer a day) [43]. A study by Koppen et al. showed that scleral lenses reduce the need for corneal transplants in severe keratoconus, with 40 out of 51 eyes successfully treated with long-term scleral lens wear instead of undergoing corneal transplant surgery and a mean gain in VA (lens vs. spectacle-corrected VA) of
$0.54 \pm 0.18$ (decimal) [44]. SoftPerm hybrid lenses are also effective with $83.3 \%$ achieving $20 / 40$ or better VA [45]. However, SoftPerm lenses were fraught with complications such as corneal neovascularization, poor tear exchange, and tearing of the lens at the junction of the soft and GP portions and as such, these lenses were discontinued in 2010.

\section{Post corneal cross-linking}

GP lens wear post-CXL is relatively well-tolerated (Table 7), likely due to decreased corneal sensitivity and the flattening effect of CXL [46]. Unlu et al. found that after CXL, the mean duration of GP lens wear increased from $6.4 \mathrm{~h} /$ day (pre-CXL) to $12.6 \mathrm{~h} /$ day ( 3 months post-CXL) and $13.2 \mathrm{~h} /$ day (6 months post-CXL) [46]. However, certain problems have been identified in the use of GP lenses post-CXL. Sehra et al. evaluated the effect of GP lens wear after corneal cross-linking in keratoconus patients and noted that there is a delay in the regeneration of the corneal sub-basal nerve plexus when compared with spectacle lens wear after cross-linking [47].

For scleral lenses, the duration of lens wear remained stable at a mean of $16 \mathrm{~h} /$ day both pre-CXL and 1-year postCXL [48]. A good VA of 0.03 logMAR was achieved [48]. In a prospective interventional case series by Singh et al, GP lenses were fitted in post-CXL patients [49]. BCLCVA post-CXL initially worsened from a pre-operative level of $0.21 \pm 0.27 \log$ MAR to $0.51 \pm 0.15 \log$ MAR $(p=0.000)$ at 2 weeks post-CXL before gradually improving to $0.01 \pm$ $0.10 \log$ MAR $(p=0.012)$ at 6 months post-CXL. Contrast sensitivity assessed by FACT chart also improved from 1.1 \pm 3.9 to $1.3 \pm 0.2$ (lowest spatial frequency, $p=0.000$ ) and from 0 to $0.3 \pm 0.3$ (highest spatial frequency, $p=0.002$ ) at 6 months follow up. Keratometric values were also significantly reduced 6 months postoperatively and duration of contact lens use increased from $1.25 \pm 1.80 \mathrm{~h}$ preoperatively to $9 \pm 1.89$ h 6 months postoperatively $(p=0.000)$ [49].

\section{Post intrastromal corneal ring segment (ICRS)}

As a result of modification of the corneal shape after ICRS implantation, contact lens fitting may be more challenging, especially GP lens fitting. Hence the use of different types of lenses (soft, scleral, corneoscleral, and piggyback) has been investigated in patients who previously underwent ICRS implantation. Overall, these lenses show good efficacy in the treatment of keratoconus post-ICRS implantation with good VA and function (Table 7). Similar to nonICRS keratoconic patients, SCL fitting was only successful in Stage I and II keratoconus (mild to moderate), with $75 \%$ and $66.66 \%$ of post-ICRS patients respectively successfully fitted, whereas none of the patients with stage III keratoconus were fitted successfully [50]. Piggyback lenses were a 
Table 6 Old versus new classification of scleral lenses according to the Scleral Lens Education Society (SLS).

\begin{tabular}{lll}
\hline Definitions & New classification (2015) [36]—corneal/scleral bearing & Old classification (2010) [114]—diameter \\
\hline Corneal & Lens rests on the cornea only & $8.0-12.5 \mathrm{~mm}$ \\
Corneo-scleral & Corneal bearing and scleral touch & $\begin{array}{l}12.5-15.0 \mathrm{~mm} \text { (previously known as semi- } \\
\text { scleral) }\end{array}$ \\
Scleral & $\begin{array}{l}\text { Mini-scleral: scleral bearing and minimal corneal touch (Lens is up to } 6 \mathrm{~mm} \\
\text { larger than HVID) }\end{array}$ & Mini-scleral: $15.0-18.0 \mathrm{~mm}$ \\
& $\begin{array}{l}\text { Large-scleral: scleral bearing and maximum corneal touch (Lens is more than 6 } \\
\text { mm larger than HVID) }\end{array}$ & Large-scleral: $18.0-25.0 \mathrm{~mm}$ \\
& &
\end{tabular}

HVID horizontal visible iris diameter.

good alternative for such patients [50]. Kerasoft IC lenses are effective in post-ICRS patients with low rates of complications and adequate VA and wearing time [51]. Kerasoft IC lenses (14-15.50 mm) (Ultravision International Limited, Bedfordshire, UK) are custom-lathe soft SiHy lenses that allows for a customized selection of central and peripheral regions. SCL central thickness equal or superior to $0.4 \mathrm{~mm}$ affects visual function in patients post-ICRS by decreasing ocular high order aberration (HOA) and improving visual function [52]. A corneo-scleral lens (Scleracon, Lenticon, Madrid, Spain; diameter: $12.60-13.50 \mathrm{~mm}$ ) was designed with a multi-aspherical geometry design based on three curves (base curve, intermediate or small transition curve, and peripheral or scleral curve) [53]. This lens provided good VA (BCLCVA: 0.00 \pm 0.12 [logMAR]; BSCVA: $0.22 \pm 0.17$ [logMAR]; $p<$ 0.001 ), a $33 \%$ decrease in total HOAs (from $2.62 \pm 1.31$ to $1.75 \pm 1.81 \mu \mathrm{m} ; p<0.009)$ and an improvement in spatial frequencies of contrast sensitivity (all $p<0.05$ ). The lens was also comfortable with $70.37 \%$ of patients reporting high ratings of subjective visual quality and mean wear time of $11.78 \pm 3.93 \mathrm{~h} \mathrm{[53]}$.

\section{Post penetrating keratoplasty (PK)}

In patients who previously underwent (PK), contact lens wear is sometimes necessary for residual refractive error or recurrent disease. Contact lens fitting may be challenging after PK because of the corneal profile which is usually centrally flat and peripherally steep as a result of the graft-host junction. GP lenses usually lead to decentration and intolerance. The use of hydrogel lenses is limited due to the inability of these lenses to correct irregular or highly astigmatic corneas. In recent years, miniscleral RGP, scleral, and large diameter RGP lenses have been shown to be effective (Table 7). Miniscleral RGP lenses (ESCLERA $^{\mathrm{TM}}$ contact lenses-Mediphacos, Buritis, MG, Brazil) were particularly successful in post PK patients previously unable to wear GP contact lenses [54]. However, lens use was discontinued in four eyes and microbial keratitis developed in one eye during follow-up [54]. BCVA obtained with the Jupiter scleral lenses (15.6-18.4-mm diameter) (Essilor Contact Lens Division, Dallas, TX) have been shown to be better than prior spectacle refraction or habitual contact lenses (most commonly GP) by two BCVA lines [55]. Overall, $91.7 \%$ of eyes achieved functional vision with BCLCVAs (Jupiter scleral lens) of 20/40 or better [55]. Tricurve RGP lenses with large diameters (12 $\mathrm{mm}$ ) have been successfully fitted in $47 \%$ of 190 PK patients with good tolerance at the Rotterdam Eye Hospital [56].

\section{Assessing satisfaction}

Patient comfort and satisfaction while wearing contact lenses is an important factor that affects patient compliance. The relationship between rigid contact lens comfort and keratoconus disease severity is still equivocal (Table 8). In the CLEK study, Edrington et al. identified factors associated with rigid contact lens comfort in keratoconus patients and found no association between decreasing patient-reported comfort and increasing disease severity as measured by steep keratometry or first definite apical clearance lens [57]. However, $\mathrm{Wu}$ et al. found that patients with severe keratoconus showed significantly reduced wearing time, NEI-VFQ-25 scores and overall satisfaction compared with patients with mild-to-moderate keratoconus [58].

According to the CLEK study, the apical fitting relationship (flat vs. steep) does not appear to be associated with patient-reported comfort. Minimal peripheral clearance may contribute to decreased rigid contact lens comfort in keratoconus [57].

The impact of contact lens wear on quality of life in keratoconus patients appears to be similar between RGP, hybrid, soft toric, and silicone-hydrogel keratoconus lenses as can be seen by similar scores on the Contact Lens Impact on Quality of Life (CLIQ) Questionnaire [59, 60]. Scleral lenses $(17-18.2 \mathrm{~mm})$ have a higher patient-reported comfort and satisfaction as compared with habitual lenses (mainly GP but also include soft, piggyback, and hybrid lenses) though midday fogging remains a limitation for many 


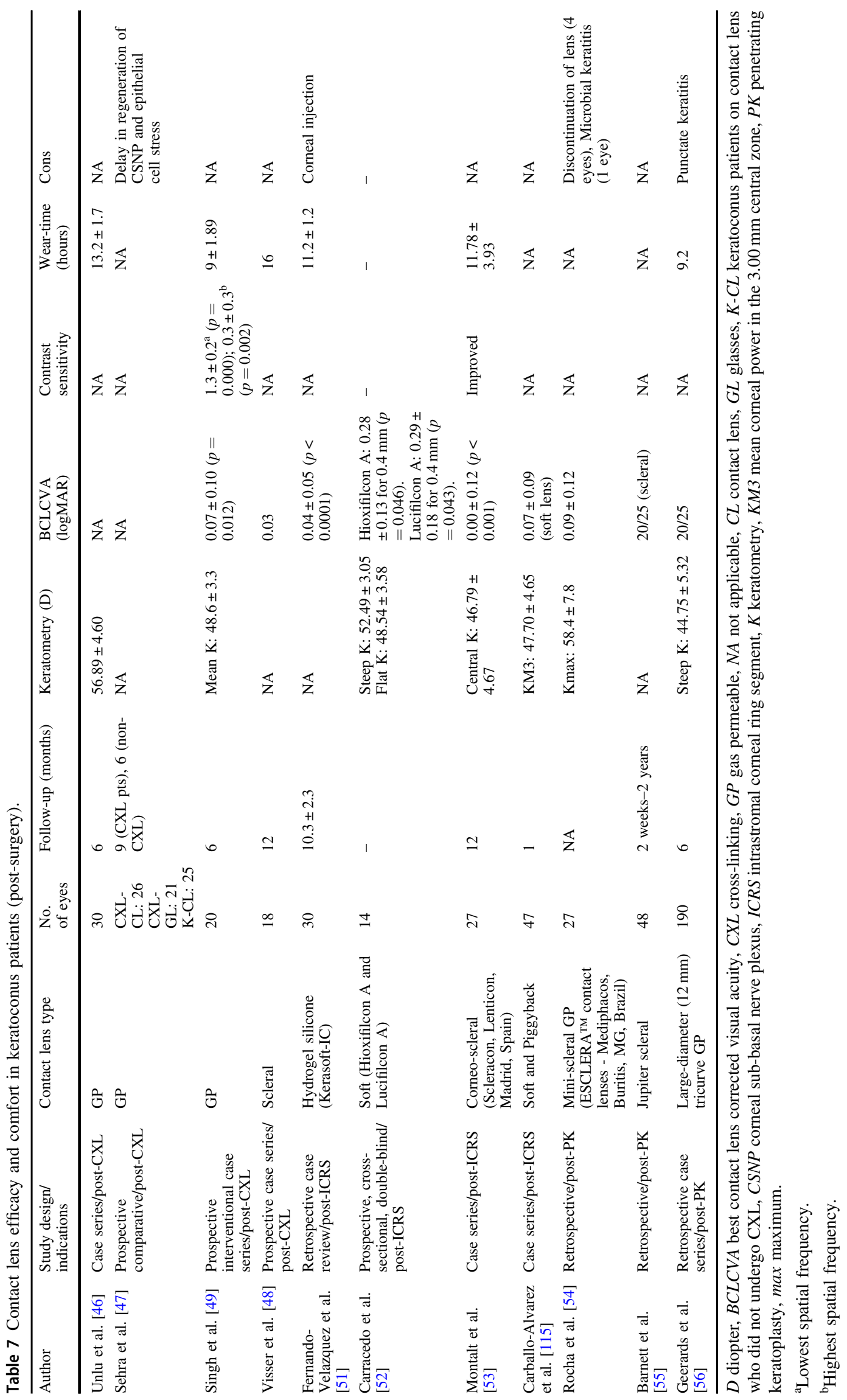




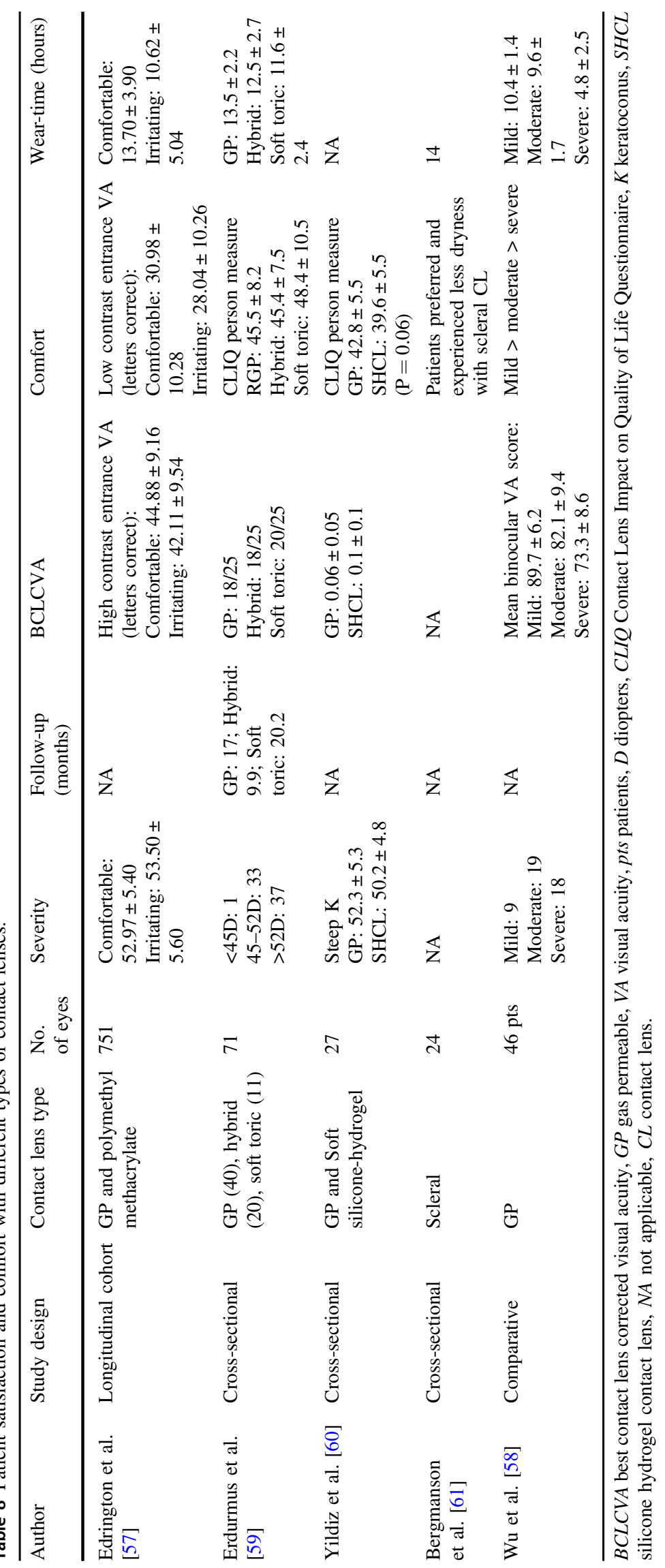


wearers [61]. Scleral lenses with their large diameter allow for vaulting over the irregular and steep corneas and also enable for more comfortable lens wear as the edge of the lens is not felt while blinking.

However, a significant limitation in the assessment of quality of life in keratoconus patients is the lack of validated quality of life questionnaires specific for the keratoconus population [62].

\section{Complications}

\section{Corneal structural changes}

Contact lens use in keratoconic patients has been associated with various structural changes such as decreased basal epithelial cell density, stromal keratocyte density, and endothelial cell count. Basal epithelial cell density has already been shown to be decreased in patients with keratoconus [63-65]. GP contact lens wear further decreases the basal epithelial cell density as compared with non-contactlens-wearing keratoconus patients [66, 67]. Patel et al. postulated that this decrease in basal epithelial cell density was due to the pathophysiology of keratoconus further worsened by contact lens wear [68]. Many studies have shown a decrease in stromal keratocyte density in keratoconic corneas as compared with normal corneas [67, 6971]. The effect of contact lens use on keratocyte density in keratoconus patients is still equivocal. Some studies have shown a further significant decrease in stromal keratocyte density in keratoconus patients who wear contact lenses (both GP and soft lenses) as compared with non-contactlens-wearing keratoconus patients [66, 69], while others report no statistically significant difference between the two groups [65, 67]. Most of these studies looked at the effect of GP lenses on the corneal structure [66, 67], one study included both GP and soft lenses [69] and one study did not specify the type of contact lens used [65]. It has been hypothesized that contact lens wear causes epithelial injury which triggers the production of apoptotic cytokines which reduce keratocyte density [69]. Conversely, a study by Acar et al. demonstrated an increase in posterior keratocyte density in piggyback and ClearKone lens wearers [72]. Endothelial cell count has been shown to be decreased by up to $18 \%$ in keratoconic patients using SoftPerm lenses but not in keratoconic patients using GP or soft lenses [70, 73]. The low oxygen permeability rates of SoftPerm lenses as compared with GP and soft lenses could explain the lower endothelial cell counts observed. Cases of significant corneal edema have also been reported in keratoconus patients wearing hybrid lenses (SoftPerm and ClearKone SynergEyes), likely due to corneal hypoxia [74, 75]. Other manifestations of corneal hypoxia in SoftPerm lens wear include peripheral corneal neovascularization [45].

\section{Dry eye}

A few studies have shown a link between keratoconus and dry eye, with a higher prevalence of clinical signs such as lower tear break up times (TBUT) and corneal staining, a higher concentration of pro-inflammatory markers such as interleukins and metalloproteinases in keratoconus patients [76-78]. GP wear has been shown to further exacerbate dry eye signs and symptoms in keratoconus patients. In a study by Carracedo et al., among keratoconus patients, GP wearers had lower Schirmer test scores and TBUT, higher diadenosine tetraphosphate (Ap4A) concentrations and higher symptom scores (McMonnies questionnaire) as compared with spectacle wearers [79]. A study by Moon et al. also found lower TBUTs and goblet cell densities in patients wearing GP for keratoconus or myopia [80]. Acar et al. found increases in IL- 6 and IL- 8 levels in keratoconus patients wearing piggyback and ClearKone contact lenses [72]. Conversely, scleral lenses have been noted to improve signs and symptoms of dry eye. A different study by Carracedo et al. showed that scleral lens wears had significantly lower Ocular Surface Disease Index scores and tear osmolarity but no changes were observed in Schirmer test scores and TBUT [81]. Ocular discomfort due to dry eye could contribute to increased eye rubbing seen in patients with keratoconus, a risk factor for keratoconus progression $[82,83]$.

\section{Keratitis}

Infectious keratitis, though rare, is one of the most sightthreatening complications of contact lens wear. The type and material of contact lens affects the risk of keratitis and there is currently no study that shows that keratoconus patients have different incidences of infective keratitis than any other patients wearing similar types of contact lenses. In an epidemiological study performed in Australia, the annualised incidence of microbial keratitis per 10,000 wearers was lowest in daily wear GP CL wearers at 1.2 (confidence interval [CI], 1.1-1.5). In order of increasing incidence of microbial keratitis per 10,000 wearers are the following lenses: daily wear soft $\mathrm{CL}$ wearers at 1.9 (CI, 1.8-2.0); daily disposable CL wearers at 2.0 (CI, 1.7-2.4); soft CL wearers (occasional overnight use) at 2.2 (CI, 2.0-2.5); daily disposable CL wearers (occasional overnight use) at 4.2 (CI, 3.1-6.6); SiHy CL wearers (occasional overnight use) at 5.5 (CI, 4.5-7.2); daily wear SiHy CL wearers at 11.9 (CI, 10.0-14.6); overnight wear soft CL wearers at 19.5 (CI, 14.6-29.5) and inovernight wear of $\mathrm{SiHy}$ at 25.4 (CI, 21.2-31.5) [84]. Hence the incidence of contact lens-related microbial keratitis was lowest in GP lens wearers, higher in soft lens wearers and the highest in overnight soft lens wearers [84]. In 
keratoconus patients, acanthamoeba keratitis has been reported in scleral lens users [85]. Possible risk factors suggested for microbial keratitis in scleral lens wearers were the large diameter of the contact lens which predisposes to corneal hypoxia, the use of large amounts of saline solution for scleral lens fitting and poor lens storage [85]. Noninfective keratitis has also been reported in a keratoconus patient wearing mini-scleral lenses [86].

\section{Fitting techniques}

There has been a change in the contact fitting technique for keratoconus over the years from an apical touch to a threepoint touch technique. Zadnik et al. reported on the safety and efficacy of flat- and steep-fitting rigid contact lenses in 761 keratoconus eyes in the CLEK study [87]. The results showed that, contrary to popular belief, keratoconic eyes fitted with an apical touch fluorescein pattern did not have an increased risk of being scarred centrally at baseline [87]. However at the end of the study there was a significant difference in the development of scarring and in the likelihood of requiring PK between flat fit lens patients and apical clearance fit lens patients. Another study compared the three-point-touch and apical touch fitting approaches in Rose K2 GP lenses in 109 eyes [88]. No statistically significant differences in optimal lens fit rates were found between three-point-touch and apical touch fitting approaches and between nipple and oval cones [88]. Sorbara et al. performed a retrospective review on the use of corneal topography to determine the types of keratoconus (centred or nipple, oval cones, severe cones or pellucid marginal degeneration (PMD)) and the type of GP lens that fitted optimally based on the type of keratoconus [89]. Inventory sets for keratoconus that had progressively smaller BOZDs (back optic zone diameter) as the base curve steepened were found to fit best when prescribed for centred or nipple cones and those that had a constant BOZD with a certain lens diameter that did not vary with the base curve were found to perform better on oval cones. Very large cones, as with PMD benefited from lenses with very large BOZDs [89].

Several studies looked at topographical predictors of the best base curve radius for GP lens fitting. The predictors include: K-minimum for pancorneal GP lens fitting [90], 5$\mathrm{mm}$ average keratometry on the axial map for Rose $\mathrm{K}$ lens fitting [91], anterior chamber depth on Pentacam corneal tomography for Esclera (R) scleral contact lens fitting [92], and mean weighted corneal sagittal height at a $7.4-\mathrm{mm}$ chord for ClearKone lens fitting [93].

Computerized contact lens fitting has been shown to reduce chair time in contact lens fitting and improve visual performance. A new web-based algorithm (free access at www.calculens.com) for selecting the back-optic zone radius of spherical GP lens in keratoconus eyes was found to improve spherical KAKC GP fitting (Conoptica) [94]. Two studies compared FITSCAN (a contact lens fitting software in built in the Orbscan ${ }^{\mathrm{TM}}$ II $\mathrm{z}$ (Bausch \& Lomb Surgical, Rochester, NY)) and conventionally fitted GP lenses and found that there was a slight bias towards flatter apical fitting in the Fitscan design $[95,96]$. One of the studies showed that selecting the $\mathrm{BC}$ of the initial trial lens $0.22 \mathrm{~mm}$ steeper than the FITSCAN calculated base curve may help to reduce the complexity of GP contact lens fitting in keratoconus [95]. Wavefront-guided scleral lens correction in keratoconus optically compensates for HOA concomitant with the disease and can provide visual image quality equivalent to that seen in normal eyes [97].

EyePrintPRO (Advanced Vision Technologies, Lakewood, Colo.), a new customized impression-guided scleral lens fitted with 3D technology, was recently developed [98]. After creating an impression mold over the ocular surface using polyvinyl siloxane material, the mold is then scanned with a 3D scanner. Lathe technology is subsequently used to create the posterior surface of the scleral lens according to the contours of the mold [98].

A piggyback lens fitting study found that negativepowered SCLs provide a flatter anterior surface in comparison with positive-powered lenses in subjects with keratoconus and thus they might be more suitable for piggyback contact lens fitting [99].

Scheimpflug imaging and anterior segment optical coherent tomography (ASOCT) are useful in scleral contact lens fitting [92, 100]. Pentacam (Oculus, Germany) measurements such as anterior chamber depth and pentacammeasured corneal height can be good predictors of the most appropriate Esclera lens to be fitted in keratoconus patients [92]. Likewise, corneal sagittal height measured with Visante OCT (Carl Zeiss, Germany) is an effective method of determining the appropriate lens/cornea relationship for scleral contact lenses [100]. The scleral lens vault (PROSE, Boston Foundation for Sight, Needham Heights, MA, USA) measured with ASOCT reduced significantly after $4 \mathrm{~h}$ of lens wear during scleral lens trial indicating that the final assessment of the scleral lens may be performed after $4 \mathrm{~h}$ of lens wear [101]. In another study, the corneal sagittal height measured with the Visante OCT showed a likelihood of clearance loss after $1 \mathrm{~h}$ of scleral lens wear [102]. Esen et al. looked at the influence of apical clearance on mini-scleral lens settling, clinical performance, and corneal thickness changes [103]. The average amount of settling was $62.8 \mu \mathrm{m}$ after $8 \mathrm{~h}, 80 \%$ of which occurred during the first $4 \mathrm{~h}$. Settling rate was significantly lower in the low apical clearance group $(P=0.01)$ with the smaller diameter lenses settling more $(P=0.03)$. Slight corneal swelling $(1.3 \%)$ occurred after $8 \mathrm{~h}$ of wear. Another study looked at anterior corneal curvature and aberration changes after scleral lens wear in 
keratoconus patients with and without ring segments and found that short-term scleral lens wear showed flattening of the anterior corneal surface in all subjects [50].

Spectral domain OCT can image and measure the tear film thickness in keratoconic patients with different fitting patterns of GP lenses, in particular Rose $\mathrm{K} 2$ lenses and can be used to evaluate and modify the lens parameters to increase patient satisfaction. Lens intolerance may be related to edge lift rather than central fitting [104].

\section{Conclusion}

Despite advances in the surgical treatment of keratoconus, contact lenses remain an important and popular option for visual rehabilitation in keratoconus, with various designs enabling a large proportion of patients to attain satisfactory VA. [12-14, 16-18, 57] New contact lens designs and materials have significantly expanded the available fitting options for keratoconus patients.

GP lens wear provided significantly better vision and improved three-dimensional depth perception as compared with glasses [20, 21]. Among GP lens types, special cone lens design lenses such as Rose $\mathrm{K}$ lenses had better patient comfort levels though there was no difference in BCLCVA among the GP lenses [19-21, 23].

Soft lenses show good efficacy for the treatment of mildto-moderate keratoconus with newer designs improving visual performance such as customised hydrogel contact lenses incorporating vertical coma correction and novel pinhole soft lens reducing higher order aberrations [29-31].

Scleral and hybrid lenses provide good VA and comfort for keratoconic patients, some of whom were previously intolerant to GP lenses [37-43]. Newer design scleral lenses have expanded the scope and comfort of contact lens wear for keratoconus patients. GP lens wear post-CXL is relatively well-tolerated, likely due to decreased corneal sensitivity and the flattening effect of CXL [46]. Contact lenses may still be required post intrastromal corneal ring procedures and post keratoplasty and in these conditions, custom soft lenses and scleral lenses are more successful than GP lenses due to the altered post-surgical corneal shape.

Imaging technology, such as corneal topography and anterior segment optical coherence tomography, can be utilized to guide contact lens fitting and to better understand the corneal microstructural changes associated with contact lens wear. Several topographical predictors of the best base curve radius for GP, scleral and hybrid lens fitting and computerized contact lens fitting techniques are now available which reduce the complexity and chair time of lens fitting as well as improving comfort and visual performance [90-97]. A new customized impression-guided scleral lens fitted with 3D technology was recently developed which further improved the accuracy of scleral lens fitting [98].

Future areas of research such as comparative studies to analyse the efficacy and comfort of the various contact lens types and validated quality of life questionnaires specific to the keratoconus population would enhance discussion on this subject. Another area of future research would be to compare the outcome of contemporary surgical options for keratoconus to that of contact lens wear.

\section{Compliance with ethical standards}

Conflict of interest The authors declare that they have no conflict of interest.

Publisher's note Springer Nature remains neutral with regard to jurisdictional claims in published maps and institutional affiliations.

\section{References}

1. Rabinowitz YS. Keratoconus. Surv Ophthalmol. 1998;42: 297-319.

2. Kennedy RH, Bourne WM, Dyer JA. A 48-year clinical and epidemiologic study of keratoconus. Am J Ophthalmol. 1986; 101:267-73.

3. Godefrooij DA, de Wit GA, Uiterwaal CS, Imhof SM, Wisse RP. Age-specific incidence and prevalence of keratoconus: a nationwide registration study. Am J Ophthalmol. 2017;175: 169-72.

4. Gordon-Shaag A, Millodot M, Shneor E, Liu Y. The genetic and environmental factors for keratoconus. Biomed Res Int. 2015;2015:795738.

5. Kymes SM, Walline JJ, Zadnik K, Gordon MO. Collaborative longitudinal evaluation of keratoconus study G. Quality of life in keratoconus. Am J Ophthalmol. 2004;138:527-35.

6. Garcia-Ferrer FJ, Akpek EK, Amescua G, Farid M, Lin A, Rhee $\mathrm{MK}$, et al. Corneal ectasia preferred practice pattern(R). Ophthalmology. 2019;126:P170-P215.

7. Mannis MJ, Zadnik K. Contact lens fitting in keratoconus. CLAO J. 1989;15:282-9.

8. Gomes JA, Tan D, Rapuano CJ, Belin MW, Ambrosio R Jr., Guell JL, et al. Global consensus on keratoconus and ectatic diseases. Cornea. 2015;34:359-69.

9. Weed KH, Macewen CJ, McGhee CN. The Dundee University Scottish Keratoconus Study II: a prospective study of optical and surgical correction. Ophthalmic Physiol Opt. 2007; 27:561-7.

10. Zadnik K, Barr JT, Edrington TB, Everett DF, Jameson M, McMahon TT, et al. Baseline findings in the Collaborative Longitudinal Evaluation of Keratoconus (CLEK) Study. Investig Ophthalmol Vis Sci. 1998;39:2537-46.

11. Wagner H, Barr JT, Zadnik K. Collaborative Longitudinal Evaluation of Keratoconus (CLEK) Study: methods and findings to date. Cont Lens Anterior Eye. 2007;30:223-32.

12. Lim N, Vogt U. Characteristics and functional outcomes of 130 patients with keratoconus attending a specialist contact lens clinic. Eye. 2002;16:54-59.

13. Fatima T, Acharya MC, Mathur U, Barua P. Demographic profile and visual rehabilitation of patients with keratoconus attending contact lens clinic at a tertiary eye care centre. Cont Lens Anterior Eye. 2010;33:19-22. 
14. Shneor E, Millodot M, Blumberg S, Ortenberg I, Behrman S, Gordon-Shaag A. Characteristics of 244 patients with keratoconus seen in an optometric contact lens practice. Clin Exp Optom. 2013;96:219-24.

15. Wei RH, Khor WB, Lim L, Tan DT. Contact lens characteristics and contrast sensitivity of patients with keratoconus. Eye Contact Lens. 2011;37:307-11.

16. Szczotka LB, Barr JT, Zadnik K. A summary of the findings from the Collaborative Longitudinal Evaluation of Keratoconus (CLEK) Study. CLEK Study Group. Optometry. 2001;72: 574-84.

17. Bilgin LK, Yilmaz S, Araz B, Yuksel SB, Sezen T. 30 years of contact lens prescribing for keratoconic patients in Turkey. Cont Lens Anterior Eye. 2009;32:16-21.

18. Pullum KW, Whiting MA, Buckley RJ. Scleral contact lenses: the expanding role. Cornea. 2005;24:269-77.

19. Gupta R, Sinha R, Singh P, Sharma N, Tandon R, Titiyal JS. Rose-K versus Soper contact lens in keratoconus: a randomized comparative trial. Middle East Afr J Ophthalmol. 2014;21: $50-55$.

20. Kazanci B, Ozek D, Anayol A, Balikci A, Ileri D, Yilmazbas P. Applications of different types of gas-permeable contact lenses in keratoconus and their visual results. Eur $\mathbf{J}$ Ophthalmol. 2014;24:835-41.

21. Nilagiri VK, Metlapally S, Kalaiselvan P, Schor CM, Bharadwaj SR. LogMAR and stereoacuity in keratoconus corrected with spectacles and rigid gas-permeable contact lenses. Optom Vis Sci. 2018;95:391-8.

22. Fernandez-Velazquez FJ. Kerasoft IC compared to Rose-K in the management of corneal ectasias. Cont Lens Anterior Eye. 2012;35:175-9.

23. Betts AM, Mitchell GL, Zadnik K. Visual performance and comfort with the Rose K lens for keratoconus. Optom Vis Sci. 2002;79:493-501.

24. Levit A, Benwell M, Evans BJW. Randomised controlled trial of corneal vs. scleral rigid gas permeable contact lenses for keratoconus and other ectatic corneal disorders. Cont Lens Anterior Eye. 2020;S1367-0484(19)30268-1.

25. Hassani M, Jafarzadehpur E, Mirzajani A, Yekta A, Khabazkhoob M. A comparison of the visual acuity outcome between Clearkone and RGP lenses. J Curr Ophthalmol. 2018;30:85-86.

26. Carracedo G, Gonzalez-Meijome JM, Lopes-Ferreira D, Carballo J, Batres L. Clinical performance of a new hybrid contact lens for keratoconus. Eye Contact Lens. 2014;40:2-6.

27. Hashemi H, Shaygan N, Asgari S, Rezvan F, Asgari S. ClearKone-Synergeyes or rigid gas-permeable contact lens in keratoconic patients: a clinical decision. Eye Contact Lens. 2014;40:95-98.

28. Pilskalns B, Fink BA, Hill RM. Oxygen demands with hybrid contact lenses. Optom Vis Sci. 2007;84:334-42.

29. Sultan P, Dogan C, Iskeleli G. A retrospective analysis of vision correction and safety in keratoconus patients wearing Toris $\mathrm{K}$ soft contact lenses. Int Ophthalmol. 2016;36: 799-805.

30. Katsoulos C, Karageorgiadis L, Vasileiou N, Mousafeiropoulos T, Asimellis G. Customized hydrogel contact lenses for keratoconus incorporating correction for vertical coma aberration. Ophthalmic Physiol Opt. 2009;29:321-9.

31. Kalikivayi L, Ajitha Vilasendran J, Chettupuzha Lonappan A, Cherian Jacob S, Kalikivayi V. A novel method in correcting aberropia using pin hole soft contact lenses: a case report. Cont Lens Anterior Eye. 2018;42:334-8.

32. Lunardi LH, Arroyo D, Andrade Sobrinho MV, Lipener C, Rosa JM. Descriptive analysis of the type and design of contact lenses fitted according to keratoconus severity and morphology. Arq Bras Oftalmol. 2016;79:82-84.
33. Szczotka-Flynn LB, Patel S. Menicon Z rigid gas permeable lenses for keratoconus and irregular corneas: a retrospective case series. Eye Contact Lens. 2008;34:254-60.

34. Kang YS, Park YK, Lee JS, Lee SU, Shin JH, Han YS, et al. The effect of the YK lens in keratoconus. Ophthalmic Physiol Opt. 2010;30:267-73.

35. Lee JL, Kim MK. Clinical performance and fitting characteristics with a multicurve lens for keratoconus. Eye Contact Lens. 2004;30:20-24.

36. van der Worp E. A guide to scleral lens fitting. 2nd ed. Books and Monographs. United States of America: Pacific University Common Knowledge; 2015.

37. Romero-Jimenez M, Flores-Rodriguez P. Utility of a semi-scleral contact lens design in the management of the irregular cornea. Cont Lens Anterior Eye. 2013;36:146-50.

38. Looi AL, Lim L, Tan DT. Visual rehabilitation with new-age rigid gas-permeable scleral contact lenses-a case series. Ann Acad Med Singap. 2002;31:234-7.

39. Baran I, Bradley JA, Alipour F, Rosenthal P, Le HG, Jacobs DS. PROSE treatment of corneal ectasia. Cont Lens Anterior Eye. 2012;35:222-7.

40. Pecego M, Barnett M, Mannis MJ, Durbin-Johnson B. Jupiter Scleral Lenses: the UC Davis Eye Center experience. Eye Contact Lens. 2012;38:179-82.

41. Kim S, Lee JS, Park YK, Lee SU, Park YM, Lee JH, et al. Fitting miniscleral contact lenses in Korean patients with keratoconus. Clin Exp Optom. 2017;100:375-9.

42. Visser ES, Van der Linden BJ, Otten HM, Van der Lelij A, Visser R. Medical applications and outcomes of bitangential scleral lenses. Optom Vis Sci. 2013;90:1078-85.

43. Otten HM, van der Linden B, Visser ES. Clinical performance of a new bitangential mini-scleral Lens. Optom Vis Sci. 2018;95: $515-22$.

44. Koppen C, Kreps EO, Anthonissen L, Van Hoey M, Dhubhghaill SN, Vermeulen L. Scleral Lenses reduce the need for corneal transplants in severe keratoconus. Am J Ophthalmol. 2018;185:43-47.

45. Ozkurt Y, Oral Y, Karaman A, Ozgur O, Dogan OK. A retrospective case series: use of SoftPerm contact lenses in patients with keratoconus. Eye Contact Lens. 2007;33:103-5.

46. Unlu M, Yuksel E, Bilgihan K. Effect of corneal cross-linking on contact lens tolerance in keratoconus. Clin Exp Optom. 2017;100:369-74.

47. Sehra SV, Titiyal JS, Sharma N, Tandon R, Sinha R. Change in corneal microstructure with rigid gas permeable contact lens use following collagen cross-linking: an in vivo confocal microscopy study. Br J Ophthalmol. 2014;98:442-7.

48. Visser ES, Soeters N, Tahzib NG. Scleral lens tolerance after corneal cross-linking for keratoconus. Optom Vis Sci. 2015;92: 318-23.

49. Singh K, Bhattacharyya M, Arora R, Dangda S, Mutreja A. Alterations in contact lens fitting parameters following crosslinking in keratoconus patients of Indian ethnicity. Int Ophthalmol. 2018;38:1521-30.

50. Serramito-Blanco M, Carpena-Torres C, Carballo J, Pinero D, Lipson M, Carracedo G. Anterior corneal curvature and aberration changes after scleral lens wear in keratoconus patients with and without ring segments. Eye Contact Lens. 2018;45:141-8.

51. Fernandez-Velazquez FJ, Fernandez-Fidalgo MJ. Feasibility of custom-made hydrogel contact lenses in keratoconus with previous implantation of intracorneal ring segments. Cont Lens Anterior Eye. 2015;38:351-6.

52. Carracedo G, Canales J, Gonzalez P, Recchioni A, CarpenaTorres C, Carballo-Alvarez J. The effect of soft contact lens thickness in visual function after intracorneal ring segments surgery. Cont Lens Anterior Eye. 2018;41:180-6. 
53. Montalt JC, Porcar E, Espana-Gregori E, Peris-Martinez C. Visual quality with corneo-scleral contact lenses after intracorneal ring segment (ICRS) implantation for keratoconus management. Cont Lens Anterior Eye. 2019;42:111-6.

54. Rocha GA, Miziara PO, Castro AC, Rocha AA. Visual rehabilitation using mini-scleral contact lenses after penetrating keratoplasty. Arq Bras Oftalmol. 2017;80:17-20.

55. Barnett M, Lien V, Li JY, Durbin-Johnson B, Mannis MJ. Use of scleral lenses and miniscleral lenses after penetrating keratoplasty. Eye Contact Lens. 2016;42:185-9.

56. Geerards AJ, Vreugdenhil W, Khazen A. Incidence of rigid gaspermeable contact lens wear after keratoplasty for keratoconus. Eye Contact Lens. 2006;32:207-10.

57. Edrington TB, Gundel RE, Libassi DP, Wagner H, Pierce GE, Walline JJ, et al. Variables affecting rigid contact lens comfort in the collaborative longitudinal evaluation of keratoconus (CLEK) study. Optom Vis Sci. 2004;81:182-8.

58. Wu Y, Tan Q, Zhang W, Wang J, Yang B, Ma W, et al. Rigid gas-permeable contact lens related life quality in keratoconic patients with different grades of severity. Clin Exp Optom. 2015;98:150-4.

59. Erdurmus M, Yildiz EH, Abdalla YF, Hammersmith KM, Rapuano CJ, Cohen EJ. Contact lens related quality of life in patients with keratoconus. Eye Contact Lens. 2009;35:123-7.

60. Yildiz EH, Erdurmus M, Elibol ES, Acar B, Vural ET. Contact lens impact on quality of life in keratoconus patients: rigid gas permeable versus soft silicone-hydrogel keratoconus lenses. Int $\mathbf{J}$ Ophthalmol. 2015;8:1074-7.

61. Bergmanson JP, Walker MK, Johnson LA. Assessing scleral contact lens satisfaction in a keratoconus population. Optom Vis Sci. 2016;93:855-60.

62. Kandel H, Pesudovs K, Watson SL. Measurement of quality of life in keratoconus. Cornea. 2020;39:386-93.

63. Niederer RL, Perumal D, Sherwin T, McGhee CN. Laser scanning in vivo confocal microscopy reveals reduced innervation and reduction in cell density in all layers of the keratoconic cornea. Investig Ophthalmol Vis Sci. 2008;49: 2964-70.

64. Weed KH, MacEwen CJ, Cox A, McGhee CN. Quantitative analysis of corneal microstructure in keratoconus utilising in vivo confocal microscopy. Eye. 2007;21:614-23.

65. Mocan MC, Yilmaz PT, Irkec M, Orhan M. In vivo confocal microscopy for the evaluation of corneal microstructure in keratoconus. Curr Eye Res. 2008;33:933-9.

66. Bitirgen G, Ozkagnici A, Malik RA, Oltulu R. Evaluation of contact lens-induced changes in keratoconic corneas using in vivo confocal microscopy. Invest Ophthalmol Vis Sci. 2013;54:5385-91.

67. Yeniad B, Yilmaz S, Bilgin LK. Evaluation of the microstructure of cornea by in vivo confocal microscopy in contact lens wearing and non-contact lens wearing keratoconus patients. Cont Lens Anterior Eye. 2010;33:167-70.

68. Patel DV, Ku JY, Johnson R, McGhee CN. Laser scanning in vivo confocal microscopy and quantitative aesthesiometry reveal decreased corneal innervation and sensation in keratoconus. Eye. 2009;23:586-92.

69. Erie JC, Patel SV, McLaren JW, Nau CB, Hodge DO, Bourne WM. Keratocyte density in keratoconus. A confocal microscopy study(a). Am J Ophthalmol. 2002;134:689-95.

70. Edmonds CR, Wung SF, Husz MJ, Pemberton B. Corneal endothelial cell count in keratoconus patients after contact lens wear. Eye Contact Lens. 2004;30:54-58.

71. Hollingsworth JG, Efron N, Tullo AB. In vivo corneal confocal microscopy in keratoconus. Ophthalmic Physiol Opt. 2005;25: 254-60.
72. Acar BT, Vural ET, Acar S. Effects of contact lenses on the ocular surface in patients with keratoconus: piggyback versus ClearKone hybrid lenses. Eye Contact Lens. 2012;38: 43-48.

73. Dogan C, Hagverdiyeva S, Mergen B, Iskeleli G. Effect of the rigid gas-permeable contact lens use on the endothelial cells in patients with keratoconus. Eye Contact Lens. 2018;44(Suppl 2): S314-S317.

74. Owens H, Watters G, Gamble G. Effect of softperm lens wear on corneal thickness and topography: a comparison between keratoconic and normal corneae. CLAO J. 2002;28:83-87.

75. Fernandez-Velazquez FJ. Severe epithelial edema in Clearkone SynergEyes contact lens wear for keratoconus. Eye Contact Lens. 2011;37:381-5.

76. Dogru M, Karakaya H, Ozcetin H, Erturk H, Yucel A, Ozmen A, et al. Tear function and ocular surface changes in keratoconus. Ophthalmology. 2003;110:1110-8.

77. Cho KJ, Mok JW, Choi MY, Kim JY, Joo CK. Changes in corneal sensation and ocular surface in patients with asymmetrical keratoconus. Cornea. 2013;32:205-10.

78. Carracedo G, Recchioni A, Alejandre-Alba N, Martin-Gil A, Crooke A, Morote IJ, et al. Signs and symptoms of dry eye in keratoconus patients: a pilot study. Curr Eye Res. 2015;40: 1088-94.

79. Carracedo G, Gonzalez-Meijome JM, Martin-Gil A, Carballo J, Pintor J. The influence of rigid gas permeable lens wear on the concentrations of dinucleotides in tears and the effect on dry eye signs and symptoms in keratoconus. Cont Lens Anterior Eye. 2016;39:375-9.

80. Moon JW, Shin KC, Lee HJ, Wee WR, Lee JH, Kim MK. The effect of contact lens wear on the ocular surface changes in keratoconus. Eye Contact Lens. 2006;32:96-101.

81. Carracedo G, Blanco MS, Martin-Gil A, Zicheng W, Alvarez JC, Pintor J. Short-term effect of scleral lens on the dry eye biomarkers in keratoconus. Optom Vis Sci. 2016;93:150-7.

82. McMonnies CW. Mechanisms of rubbing-related corneal trauma in keratoconus. Cornea. 2009;28:607-15.

83. Yeniad B, Alparslan N, Akarcay K. Eye rubbing as an apparent cause of recurrent keratoconus. Cornea. 2009;28:477-9.

84. Stapleton F, Keay L, Edwards K, Naduvilath T, Dart JK, Brian $\mathrm{G}$, et al. The incidence of contact lens-related microbial keratitis in Australia. Ophthalmology. 2008;115:1655-62.

85. Sticca MP, Carrijo-Carvalho LC, Silva IMB, Vieira LA, Souza LB, Junior RB, et al. Acanthamoeba keratitis in patients wearing scleral contact lenses. Cont Lens Anterior Eye. 2018;41:307-10.

86. Bruce AS, Nguyen LM. Acute red eye (non-ulcerative keratitis) associated with mini-scleral contact lens wear for keratoconus. Clin Exp Optom. 2013;96:245-8.

87. Zadnik K, Barr JT, Steger-May K, Edrington TB, McMahon TT, Gordon $\mathrm{MO}$, et al. Comparison of flat and steep rigid contact lens fitting methods in keratoconus. Optom Vis Sci. 2005;82: 1014-21.

88. Romero-Jimenez M, Santodomingo-Rubido J, GonzalezMeijome JM. An assessment of the optimal lens fit rate in keratoconus subjects using three-point-touch and apical touch fitting approaches with the rose K2 lens. Eye Contact Lens. 2013; 39:269-72.

89. Sorbara L, Dalton K. The use of video-keratoscopy in predicting contact lens parameters for keratoconic fitting. Cont Lens Anterior Eye. 2010;33:112-8.

90. Ramdas WD, Vervaet CJ, Bleyen I. Corneal topography for pancorneal toric edge rigid gas-permeable contact lens fitting in patients with keratoconus, and differences in age and gender. Cont Lens Anterior Eye. 2014;37:20-25. 
91. Mandathara Sudharman P, Rathi V, Dumapati S. Rose K lenses for keratoconus-an Indian experience. Eye Contact Lens. 2010;36:220-2.

92. Weber SL, Ambrosio R Jr., Lipener C, Coral-Ghanem C, Hofling-Lima AL. The use of ocular anatomical measurements using a rotating Scheimpflug camera to assist in the Esclera(R) scleral contact lens fitting process. Cont Lens Anterior Eye. 2016;39:148-53.

93. Downie LE. Predictive value of corneal topography for ClearKone hybrid contact lenses. Optom Vis Sci. 2013;90: e191-197.

94. Ortiz-Toquero S, Rodriguez G, de Juan V, Martin R. New web-based algorithm to improve rigid gas permeable contact lens fitting in keratoconus. Cont Lens Anterior Eye. 2017;40: 143-50.

95. Mandathara PS, Fatima M, Taureen S, Dumpati S, Ali MH, Rathi V. RGP contact lens fitting in keratoconus using FITSCAN technology. Cont Lens Anterior Eye. 2013;36:126-9.

96. Bhatoa NS, Hau S, Ehrlich DP. A comparison of a topographybased rigid gas permeable contact lens design with a conventionally fitted lens in patients with keratoconus. Cont Lens Anterior Eye. 2010;33:128-35.

97. Marsack JD, Ravikumar A, Nguyen C, Ticak A, Koenig DE, Elswick JD, et al. Wavefront-guided scleral lens correction in keratoconus. Optom Vis Sci. 2014;91:1221-30.

98. Nguyen MTB, Thakrar V, Chan CC. EyePrintPRO therapeutic scleral contact lens: indications and outcomes. Can J Ophthalmol. 2018;53:66-70.

99. Romero-Jimenez M, Santodomingo-Rubido J, Flores-Rodriguez $\mathrm{P}$, Gonzalez-Meijome JM. Which soft contact lens power is better for piggyback fitting in keratoconus? Cont Lens Anterior Eye. 2013;36:45-48.

100. Otchere H, Jones L, Sorbara L. The impact of scleral contact lens vault on visual acuity and comfort. Eye Contact Lens.2018;44 Suppl 2:S54-S59.

101. Rathi VM, Mandathara PS, Dumpati S, Sangwan VS. Change in vault during scleral lens trials assessed with anterior segment optical coherence tomography. Cont Lens Anterior Eye. 2017;40:157-61.

102. Otchere H, Jones LW, Sorbara L. Effect of time on scleral lens settling and change in corneal clearance. Optom Vis Sci. 2017;94:908-13.
103. Esen F, Toker E. Influence of apical clearance on mini-scleral lens settling, clinical performance, and corneal thickness changes. Eye Contact Lens. 2017;43:230-5.

104. Elbendary AM, Abou Samra W. Evaluation of rigid gas permeable lens fitting in keratoconic patients with optical coherence tomography. Graefes Arch Clin Exp Ophthalmol. 2013;251:1565-70.

105. Rashid ZA, Millodot M, Evans KS. Characteristics of keratoconic patients attending a specialist contact lens clinic in Kenya. Middle East Afr J Ophthalmol. 2016;23:283-7.

106. Gumus K, Kahraman N. A new fitting approach for providing adequate comfort and visual performance in keratoconus: soft HydroCone (Toris K) lenses. Eye Contact Lens 2016;42:225-30.

107. Nejabat M, Khalili MR, Dehghani C. Cone location and correction of keratoconus with rigid gas-permeable contact lenses. Cont Lens Anterior Eye. 2012;35:17-21.

108. Kamar S, Vervaet C, Luyten GP, Jager MJ. Pancorneal contact lens with a toric edge: a new concept in keratoconus. Eur J Ophthalmol. 2011;21:685-90.

109. Yanai R, Ueda K, Nishida T. Retrospective analysis of vision correction and lens tolerance in keratoconus patients prescribed a contact lens with dual aspherical curves. Eye Contact Lens. 2010;36:86-89.

110. Jain AK, Sukhija J. Rose-K contact lens for keratoconus. Indian J Ophthalmol. 2007;55:121-5.

111. Arumugam AO, Rajan R, Subramanian M, Mahadevan R. PROSE for irregular corneas at a tertiary eye care center. Eye Contact Lens. 2014;40:71-73.

112. Rathi VM, Dumpati S, Mandathara PS, Taneja MM, Sangwan VS. Scleral contact lenses in the management of pellucid marginal degeneration. Cont Lens Anterior Eye. 2016;39:217-20.

113. Montalt JC, Porcar E, Espana-Gregori E, Peris-Martinez C. Visual quality with corneo-scleral contact lenses for keratoconus management. Cont Lens Anterior Eye. 2018;S1367-0484(17) 30270-9.

114. van der Worp E. A Guide to Scleral Lens Fitting. Books and Monographs. United States of America: Pacific University Common Knowledge; 2010.

115. Carballo-Alvarez J, Puell MC, Cuina R, Diaz-Valle D, Vazquez JM, Benitez-Del-Castillo JM. Soft contact lens fitting after intrastromal corneal ring segment implantation to treat keratoconus. Cont Lens Anterior Eye. 2014;37:377-81. 